\title{
Non-hydrolytic sol-gel route to a family of hybrid mesoporous aluminosilicate ethanol dehydration catalysts
}

Ales Styskalik, ${ }^{a, b}$ Imene Kordoghli, ${ }^{a}$ Claude Poleunis, ${ }^{a}$ Arnaud Delcorte, ${ }^{a}$ Denis Dochain, ${ }^{a}$ Zdenek Moravec, ${ }^{\text {b Julius Vida, }}{ }^{\mathrm{c}}$ Tomas Homola, ${ }^{\mathrm{c}}$ Carmela Aprile, ${ }^{\mathrm{d}}$ Luca Fusaro, ${ }^{\mathrm{d}}$ François Devred, ${ }^{a}$ Damien P. Debecker*a

${ }^{a}$ Institute of Condensed Matter and Nanosciences (IMCN), Université catholique de Louvain (UCLouvain), Place Louis Pasteur 1, 1348 Louvain-La-Neuve, Belgium

${ }^{b}$ Department of Chemistry, Masaryk University, Kotlarska 2, CZ-61137 Brno, Czech Republic ${ }^{c}$ R\&D Center for Low-Cost Plasma and Nanotechnology Surface Modifications (CEPLANT), Department of Physical Electronics, Masaryk University, Kotlarska 2, CZ-61137 Brno, Czech Republic

${ }^{d}$ Department of Chemistry, Unit of Nanomaterials Chemistry, University of Namur, 5000 Namur, Belgium

*Corresponding author (damien.debecker@uclouvain.be). 


\section{ABSTRACT}

Organic-inorganic hybrid materials are nowadays intensely studied for potential applications in heterogeneous catalysis because their properties and catalytic behavior differ from pristine inorganic counterparts. The organic groups at the catalyst surface can modify not only its hydrophilicity, but also acidity, hydrothermal stability, porosity, etc. In some cases, such properties alteration leads to improved catalytic performance in terms of activity, selectivity, or stability. However, the choice of organic groups stays relatively narrow, as most reports focus on pendant methyl groups. Here, a series of mesoporous hybrid aluminosilicate materials containing various organic groups was prepared in one pot by nonhydrolytic sol-gel (NHSG). Both aromatic and aliphatic, pendant and bridging organic groups were incorporated. The presence of the organic groups in the bulk and the outermost surface of the materials was verified by solid-state NMR and ToF-SIMS, respectively. Aluminum is mostly incorporated in tetrahedral coordination in the hybrid silica matrix. The organically modified mesoporous aluminosilicate samples were tested as catalysts in the gas phase ethanol dehydration (which relies on solid acids) and most of them outperformed the purely inorganic catalyst benchmark. While a direct influence of surface hydrophilicity or hydrophobicity (as probed by water sorption and water contact angle measurements) appeared unlikely, characterization of acidity (IR-pyridine) revealed that the improved performance for hybrid catalysts can be correlated with a modification of the acidic properties. In turn, acidity is determined by the quality of the dispersion of Al centers in the form of isolated sites in the hybrid silica matrix. All in all, this study establishes a "ranking" for a variety of organic groups in terms of their effect on gas-phase ethanol dehydration to ethylene; ethylene yield decreases in this order: bridging xylylene $\approx$ pendant methyl > pendant benzyl > bridging methylene $\approx$ inorganic benchmark (no organic groups) $>$ bridging ethylene.

Keywords: non-hydrolytic sol-gel, hybrid aluminosilicate; hydrophobicity; acidity; heterogeneous catalysis; ethanol dehydration 


\section{Introduction}

Hybrid organic-inorganic materials based on silica have recently attracted considerable attention because of their possible application in catalysis, adsorption, and gas sensing ${ }^{1,2}$. In the field of heterogeneous catalysis, many publications have reported a performance boost following the introduction of organic groups into inorganic catalysts. This strategy is especially successful in organic reactions that involve the presence of water which should be repelled from the catalyst surface..$^{3-10}$

Methyl groups represent the most widely reported type of incorporated organic moieties. Application of other groups (e.g. longer aliphatic chains, aromatic rings, fluorinated organic groups) has been reported much less often. Such a broadening of applied materials however might bring other positive effects: not only hydrophobicity alteration (that may or may not be observed upon methyl groups introduction), ${ }^{3,11-13}$ including also selective adsorption of reactants induced by specific non-bonding interactions (e.g. $\pi-\pi$ stacking), ${ }^{14}$ but also porosity changes, ${ }^{15,16}$ hydrothermal stability improvement, ${ }^{17}$ or modulation of catalyst sites strength and accessibility. ${ }^{18,19}$ Functional organic groups can bring additional advantages to the final material. $^{20}$

Sol-gel chemistry and particularly co-condensation methods have emerged as simple and promising routes for the preparation of organic-inorganic hybrid catalysts. ${ }^{21,22}$ In classical sol-gel methods, molecular precursors undergo hydrolysis and inorganic polycondensation reactions to form a solid material with the desired properties; wide ranges of composition can be envisaged. Nevertheless, classical - hydrolytic - sol-gel chemistry routes face two major limitations: (i) markedly different reactivity of different precursors often leads to inhomogeneous solids and (ii) water elimination during drying tends to cause pore collapse 
due to high surface tension. One possible solution to avoid these issues is to work in nonaqueous conditions where oxo bridges are formed with the help of oxygen donors other than water. ${ }^{23,24}$ In these "non-hydrolytic sol-gel" (NHSG) routes, the reactivity of different precursors (silanes, organosilanes, and metal alkoxides, amides, halides, etc.) tends to be levelled off, leading to highly homogeneous metallosilicate materials. Also, working in organic solvents with low surface tension prevents the pores collapse during drying which leads to highly porous materials. Various organic groups (including both terminal and bridging, aliphatic and aromatic) have already been incorporated into metallosilicate materials via NHSG routes and this was reported to lead to interesting properties - high surface areas, ${ }^{15,20,25,26}$ tunable pore sizes, ${ }^{15,20,27}$ varying hydrothermal stabilities, ${ }^{27}$ and even in some cases superior catalytic activity. ${ }^{6,7,18}$ Therefore, the NHSG method presents an ideal route to porous organic-inorganic hybrid materials and in particular hybrid catalysts.

Ethanol dehydration producing ethylene (and diethylether) and water represents a model catalytic transformation, where the influence of hydrophobicity/hydrophilicity can be studied. Moreover, the dehydration of bioalcohols - e.g. bioethanol - is an important catalytic reaction in the perspective of the development of a bio-based industry. ${ }^{28-31}$ Traditional catalysts employed in this reaction are fully inorganic: alumina, silica-alumina, and HZSM-5. ${ }^{32,33}$ Each of these systems come with their own limitations: only moderate activity in the case of $\mathrm{Al}_{2} \mathrm{O}_{3}$ and silica-alumina, and rapid deactivation by coking in the case of zeolite catalysts. Application of hydrophobic hybrid materials might be beneficial in the dehydration reaction, because the surface properties (mainly hydrophilicity and acidity) can in principle be fine-tuned by the presence of the organic moieties and impact the catalytic performance. However, the use of hybrid materials to boost catalyst activity, selectivity or stability has been reported only scarcely in the case of alcohol dehydration..$^{8,34-37}$ 
In the specific case of gas-phase ethanol dehydration to ethylene, we have shown two important factors influencing strongly the behavior of methylated metallosilicates: (i) the hydrothermal stability of Si-C bonds (which is unsatisfactory if aromatic organic groups are directly bound to Si atoms) $)^{27}$ and (ii) the number, nature, and strength of acid sites. ${ }^{12,38}$ On the other hand, studying a series of methylated aluminosilicate materials, a direct influence of hydrophobicity on the catalytic performance was not demonstrated. ${ }^{12}$

Herein we report on a series of hybrid aluminosilicates prepared by NHSG, in which the organic groups attached to the inorganic matrices were varied: bridging and terminal, aliphatic and aromatic groups were incorporated. The catalysts' structure, porosity, acidity, and hydrophobicity were followed by a number of analytical methods and correlated with performance in ethanol dehydration. By doing so, "a ranking" of organic groups is established, according to their effect on catalytic performance of the hybrid catalysts, and these are benchmarked to conventional, purely inorganic catalyst (free of organic groups).

\section{Experimental}

General. All manipulations were performed under high vacuum or dry $\mathrm{N}_{2}$ atmospheres using Schlenk techniques or in a dry box with $\mathrm{H}_{2} \mathrm{O}$ and $\mathrm{O}_{2}$ levels below $1 \mathrm{ppm}$. Diisopropylether and benzene- $\mathrm{d}_{6}$ were dried over $\mathrm{Na}$ metal. $\mathrm{CH}_{2} \mathrm{Cl}_{2}$ was dried with $\mathrm{P}_{4} \mathrm{O}_{10}$. All solvents were distilled, and stored in a glovebox over molecular sieves. Aluminum chloride $\left(A B C R, A I C l_{3}\right.$, $99.999 \%$ ), silicon tetrachloride (Sigma, $\mathrm{SiCl}_{4}, 99 \%$ ), methyltrichlorosilane (Sigma, $\mathrm{CH}_{3} \mathrm{SiCl}_{3}$, $99 \%$ ), benzyltrichlorosilane ( $\mathrm{ABCR}, \mathrm{C}_{6} \mathrm{H}_{5} \mathrm{CH}_{2} \mathrm{SiCl}_{3}, 97$ \%), (3,3,3-trifluoropropyl)trichlorosilane ( $\mathrm{ABCR}, \mathrm{CF}_{3} \mathrm{CH}_{2} \mathrm{CH}_{2} \mathrm{SiCl}_{3}, 97 \%$ ), bis(trichlorosilyl)methane ( $\mathrm{ABCR}, \mathrm{Cl}_{3} \mathrm{SiCH}_{2} \mathrm{SiCl}_{3}, 97 \%$ ), and 1,2bis(trichlorosilyl)ethane ( $\left.\mathrm{ABCR}, \mathrm{Cl}_{3} \mathrm{SiCH}_{2} \mathrm{CH}_{2} \mathrm{SiCl}_{3}, 95 \%\right)$ were stored in a glovebox and used as received. $\alpha$, $\alpha^{\prime}$-dichloro-p-xylene ( $\left.\mathrm{TCl} 98.0 \%\right)$, tripropylamine $(\mathrm{TCl}, 98 \%)$, and trichlorosilane (Sigma, $99 \%$ ) were used as received for the synthesis of 1,4bis(trichlorosilylmethyl)benzene according to literature ${ }^{39}$. Ethanol absolute (AnalaR NORMAPUR, $99.95 \%$ ) was used as received. Silica-alumina catalyst support (grade 135, SSA 
$=600 \mathrm{~m}^{2} \mathrm{~g}^{-1}, \mathrm{~V}_{\mathrm{p}}=0.76 \mathrm{~cm}^{3} \mathrm{~g}^{-1}$, Si:Al ratio $\sim$, SACS) was purchased from Sigma-Aldrich. ZSM5 zeolite in ammonium form (SSA $=400 \mathrm{~m}^{2} \mathrm{~g}^{-1}$, Si:Al ratio $\sim 15$ ) was purchased from Alfa Aesar and calcined at $500{ }^{\circ} \mathrm{C}$ in order to transform it to $\mathrm{H}+$ form (HZSM-5).

Xerogel synthesis. In a typical synthesis, diisopropylether (DIPE), organosilane ( $\mathrm{R}_{\text {pendant }} \mathrm{SiCl}_{3}$ or $\mathrm{Cl}_{3} \mathrm{Si}-\mathrm{R}_{\text {bridging }}-\mathrm{SiCl}_{3}$ ), and silicon tetrachloride were loaded in an autoclave loaded with $45 \mathrm{~cm}^{3} \mathrm{CH}_{2} \mathrm{Cl}_{2}$ in a glove box. $\mathrm{AlCl}_{3}$ (neat) was directly added to this reaction mixture with vigorous stirring and stirred at RT until complete dissolution (5-10 min). No surfactant was used in the synthesis. The organic modification degree corresponded in all cases to 1 $\mathrm{R}_{\text {pendant }} \mathrm{SiO}_{3}$ group (or $0.5 \mathrm{O}_{3} \mathrm{SiR}_{\text {bridging }} \mathrm{SiO}_{3}$ ) for $15 \mathrm{SiO}_{4}$ groups, and the $\mathrm{Si} / \mathrm{Al}$ ratio was 16 . These molar ratios were chosen according to our previous study on methylated aluminosilicates and kept for all samples prepared in this study. ${ }^{12}$ The autoclave with the reaction mixture was sealed and kept in an oven at $110{ }^{\circ} \mathrm{C}$ for $72 \mathrm{hrs}$ for gelation (Eqn. 1). After cooling down, the autoclave was put back into the glovebox, opened and the gel was transferred into a Schlenk vessel. The gels were then dried under vacuum at $60^{\circ} \mathrm{C}$ overnight in order to remove the solvent and volatile condensation product (isopropylchloride). The resulting powders were calcined in flow of dry air at $300{ }^{\circ} \mathrm{C}\left(1{ }^{\circ} \mathrm{C} \mathrm{min}-1,5 \mathrm{hrs}\right)$ yielding a brown xerogels. While the molar ratios $\left(15 \mathrm{SiO}_{4}: 1 \mathrm{RSiO}_{3}: 1 \mathrm{Al}\right.$ in case of pendant organic groups and $15 \mathrm{SiO}_{4}: 0.5 \mathrm{O}_{3} \mathrm{SiR}^{\prime} \mathrm{SiO}_{3}: 1 \mathrm{Al}$ in case of bridging organic groups), temperatures, times, etc. were kept constant throughout the whole series of syntheses, the nature of organic groups bound to silica network was varied. The catalysts are denoted $\mathbf{p} \_\mathbf{P h} \mathbf{C H}_{\mathbf{2}}, \mathbf{p} \_\mathbf{M e}, \mathbf{b} \_\mathbf{C H}_{\mathbf{2}}$, b_ $\mathbf{C}_{2} \mathrm{H}_{4}$, and $\mathbf{b} \_\mathbf{X y}$; the name explicitly refers to the type of organic functionalization (Chart 1), " $p$ " stands for pendant organic groups; "b" stands for "bridging". The incorporated organic moiety is identified by the second part of the name (e.g. benzyl groups " $\mathrm{PhCH}_{2}$ ", etc.). In order to change the nature of organic groups bound to silica, different organosilane precursors were used: benzyltrichlorosilane, methyltrichlorosilane, bis(trichlorosilyl)methane, bis(trichlorosilyl)ethane, 1,4bis(trichlorosilylmethyl)benzene, respectively. Sample p_Me has already been presented in our previous paper, where it was labeled "15Si-1MeSi-1Al"). ${ }^{12} \mathrm{~A}$ purely inorganic benchmark catalyst with the same $\mathrm{Si}: \mathrm{Al}$ nominal ratio was prepared in the same way using only $\mathrm{SiCl}_{4}$ as a silicon precursor (16Si-1Al). Precise reactant masses used in the syntheses can be found in Table 1. For the record, we also successfully incorporated trifluoropropyl groups via co- 
condensation of silicon tetrachloride with 3,3,3-trifluoropropyltrichlorosilane $\left(\mathbf{p}_{-} \mathbf{C F}_{3} \mathbf{C}_{2} \mathbf{H}_{4}\right)$ following the same synthetic protocol (see ${ }^{13} \mathrm{C}$ CPMAS NMR in ESI, Fig. 1S) but this sample had poor catalytic activity and is not discussed further in this article.

$\mathrm{AlCl}_{3}+15 \mathrm{SiCl}_{4}+\mathrm{RSiCl}_{3}+33^{i} \mathrm{PrO}^{i} \mathrm{Pr} \rightarrow \frac{1}{2} \mathrm{Al}_{2} \mathrm{O}_{3} \cdot 15 \mathrm{SiO}_{2} \cdot 1 \mathrm{RSiO}_{1.5}+66^{i} \mathrm{PrCl}$<smiles>[O-][Si](O)(O)Cc1ccccc1</smiles><smiles>CCCCC[Si](O)(O)O</smiles>

$$
\text { p_Me }
$$<smiles>C[Si]([O])(O)O</smiles>

b_CH<smiles>O[Si](O)(O)C[Si](O)(O)O</smiles><smiles>[Y10]c1cc(C[Si](O)(O)O)ccc1C[Si](O)(O)O</smiles>

Chart 1: Various organic groups attached to the aluminosilicate matrices and their labelling; $p_{-}$ stands for pendant organic group, b_ stands for bridging organic group.

Table 1: Synthesis (amount of precursors introduced in the preparation) and characterization of hybrid aluminosilicate catalysts in terms of surface (XPS) composition.

\begin{tabular}{|c|c|c|c|c|c|}
\hline Sample & $\begin{array}{l}\mathrm{n}_{\mathrm{Si}} \\
{[\mathrm{mmol}]}\end{array}$ & $\begin{array}{l}\mathrm{n}_{\mathrm{RSi}} \\
{[\mathrm{mmol}]}\end{array}$ & $\begin{array}{l}\mathrm{n}_{\mathrm{Al}} \\
{[\mathrm{mmol}]}\end{array}$ & $\begin{array}{l}\mathrm{n}_{\mathrm{DIPE}} \\
{[\mathrm{mmol}]}\end{array}$ & $\begin{array}{l}\text { Si/Al ratio } \\
\text { Theor }{ }^{\mathrm{a}} / \mathrm{XPS}[-]\end{array}$ \\
\hline p_Me ${ }^{12}$ & 26.87 & 1.779 & 1.822 & 59.89 & $15.7 / 24.2$ \\
\hline p_PhCH 2 & 26.82 & 1.809 & 1.771 & 59.27 & $16.2 / 20.2$ \\
\hline b_CH & 26.66 & 0.895 & 1.791 & 59.14 & $15.9 / 24.7$ \\
\hline b_C $\mathrm{C}_{2} \mathrm{H}_{4}$ & 26.84 & 0.939 & 1.837 & 60.08 & $15.6 / 28.0$ \\
\hline b_Xy & 26.88 & 0.894 & 1.788 & 59.02 & $16.0 / 25.5$ \\
\hline $16 \mathrm{Si}-1 \mathrm{Al} \mathrm{I}^{12}$ & 28.63 & - & 1.762 & 60.09 & $16.2 / 30.0$ \\
\hline
\end{tabular}


Characterization. Transmission IR spectra $\left(4000-400 \mathrm{~cm}^{-1}\right)$ were recorded on a Bruker Equinox 55 spectrometer from $\mathrm{KBr}$ pellets or on a Bruker Alpha-Platinum ATR system. The same instrument was used - in combination with pyridine adsorption - to quantify acid sites. ${ }^{40}$ Wafers based on ca. $30 \mathrm{mg}$ of analyzed sample were pressed and evacuated at $350{ }^{\circ} \mathrm{C}$ at $\approx 10^{-4}$ Torr overnight. Then pyridine was adsorbed at its autogenous pressure at RT for 30 min. Physisorbed pyridine was removed by evacuation at $150^{\circ} \mathrm{C}$ at $\approx 10^{-4}$ Torr for $2 \mathrm{hrs}$ and IR spectra were collected. Molar extinction coefficients according to Emeis were used for calculations for absorption bands at $1455 \mathrm{~cm}^{-1}$ (Lewis acid sites) and at $1545 \mathrm{~cm}^{-1}$ (Brønsted acid sites). ${ }^{40}$ Strength of acid sites was estimated by further evacuation/IR measurement steps at 250 and $350{ }^{\circ} \mathrm{C}$. Thermal analysis (TG/DSC) was measured on a Netzsch STA 449C Jupiter apparatus from $25-1000 \stackrel{\circ}{ } \mathrm{C}$ under flowing air $\left(70 \mathrm{~cm}^{3} \mathrm{~min}^{-1}\right)$ with a heating rate of 5 $\mathrm{K} \mathrm{min}^{-1}$. Surface areas (SA) and pore volumes were determined by nitrogen adsorption at 77.4 K by volumetric techniques ${ }^{41,42}$ on a Tristar 3000 instrument (Micromeritics, USA). Prior to measurement, the samples were degassed at $150{ }^{\circ} \mathrm{C}$ for at least $8 \mathrm{hrs}$. The specific surface area was determined by the multipoint BET method with at least five data points with relative pressures between 0.05 and 0.30 . Water adsorption was performed on a 3Flex instrument (Micromeritics) and Autosorb-iQ-MP (Quantachrome) at room temperature ( $p_{0}=$ 21 Torr). Prior to measurement, the samples were degassed at $150{ }^{\circ} \mathrm{C}$ for at least $8 \mathrm{hrs}$. The ratio of volume of adsorbed liquid $\mathrm{H}_{2} \mathrm{O}$ (calculated from $\mathrm{H}_{2} \mathrm{O}$ adsorption) and volume of adsorbed liquid $\mathrm{N}_{2}$ (calculated from $\mathrm{N}_{2}$ physisorption) at $\mathrm{p} / \mathrm{p}_{0}=0.3$ was denoted $\mathrm{X}_{0.3}$ and taken as a measure of hydrophilicity ("hydrophilicity index") similar to reports by Gounder et al. ${ }^{9}$, Olson et al. ${ }^{43}$ and Thommes et al. ${ }^{44}$. Solution NMR spectra were recorded on a Bruker $300 \mathrm{MHz}$ NMR spectrometer at frequencies $299.8 \mathrm{MHz}$ for proton and $75.4 \mathrm{MHz}$ for carbon with deuterated solvents as the external lock. The proton and carbon NMR spectra were 
referenced to the residual proton signals or carbon resonances of benzene- $d_{6}$ ( 7.15 and 128.0 ppm, respectively). Solid-state ${ }^{27} \mathrm{Al},{ }^{29} \mathrm{Si}$, and ${ }^{13} \mathrm{C}$ solid state magic angle spinning (MAS) NMR spectra were acquired on Bruker Avance-500 NMR spectrometer with a 4 mm CP-MAS Bruker probe at frequencies $99.4 \mathrm{MHz}$ for silicon, $130.3 \mathrm{MHz}$ for aluminum, and $125.8 \mathrm{MHz}$ for carbon. MAS rates were $8 \mathrm{kHz}$ for ${ }^{29} \mathrm{Si}$ and ${ }^{13} \mathrm{C}$ (CP)MAS and $10 \mathrm{kHz}$ for ${ }^{27} \mathrm{Al}$ MAS spectra. Chemical shifts were referenced externally to ${ }^{29} \mathrm{Si} \delta[3$-(trimethylsilyl)-1-propanesulfonic acid sodium salt (DSS)]: $1.53 \mathrm{ppm} ;{ }^{13} \mathrm{C} \delta\left[\right.$ adamantane $38.68 \mathrm{ppm} ;{ }^{27} \mathrm{Al} \delta\left[\left[\mathrm{Al}\left(\mathrm{H}_{2} \mathrm{O}\right)_{6}\right]^{3+}\right.$ (aq. solution)]: $0.0 \mathrm{ppm}$. X-Ray photoelectron spectroscopy (XPS) measurements were carried out on a SSI X probe spectrometer (model SSI 100, Surface Science Laboratories, Mountain View, CA) equipped with a monochromatized Al-Ka radiation (1486 eV). The sample powders, pressed in small stainless troughs of $4 \mathrm{~mm}$ diameter, were placed on an insulating homemade ceramic carousel. The pressure in the analysis chamber was around $10^{-6} \mathrm{~Pa}$. The analyzed area was approximately $1.4 \mathrm{~mm}^{2}$ and the pass energy was set at $150 \mathrm{eV}$. The C1s peak of carbon has been fixed to $284.8 \mathrm{eV}$ to set the binding energy scale for the pristine sample $16 \mathrm{Si}-1 \mathrm{Al}$ and to $284.4 \mathrm{eV}$ for the hybrid samples containing organic groups ${ }^{45}$. Data treatment was performed with the CasaXPS program (Casa Software Ltd, UK) and spectra were decomposed with the least squares fitting routine provided by the software with a Gaussian/Lorentzian (85/15) product function and after baseline was subtracted. Time of flight secondary ion mass spectrometry (ToF-SIMS) analyses conducted with a TOF.SIMS 5 instrument (IONTOF GmbH, Münster, Germany). A pulsed $\mathrm{Bi}_{5}{ }^{+}$metal ion source was used to produce a primary beam using an acceleration voltage of $30 \mathrm{kV}$. An AC target current of 0.07 pA with a bunched pulse width lower than 1 ns was used. Both positive and negative secondary ion species were analysed. Mass spectra were obtained by scanning the primary ion beam over a $250 \times 250 \mu \mathrm{m}^{2}$ area. The total primary ion beam dose for each analysed area 
was always kept below $5 \cdot 10^{10}$ ions $\mathrm{cm}^{-2}$, ensuring static conditions. Lateral resolution of $\sim 3$ $\mu \mathrm{m}$ and mass resolution $\mathrm{m} / \Delta \mathrm{m}>4000$ at $29 \mathrm{~m} / \mathrm{z}$ were maintained for positive and negative mass spectra acquisition. Charge compensation was conducted using an interlaced electron flood gun (kinetic energy $=20 \mathrm{eV}$ ). All data analyses were carried out with the software supplied by the instrument manufacturer, SurfaceLab (version 6.5). Sample powders were pressed onto the adhesive part of Post-it ${ }^{\oplus}$ papers.

Catalytic dehydration of ethanol. The calcined xerogel catalysts $(0.192 \mathrm{~g}$, sieved in the $0.20-$ $0.40 \mathrm{~mm}$ particle size range) were diluted with glass beads $(0.5-1 \mathrm{~mm})$ in order to keep the volume of the catalyst bed constant. The void space of the reactor was filled with silica beads. Catalytic testing was carried out by injecting $0.212 \mathrm{~g} \mathrm{~h}^{-1}$ of absolute ethanol by means of a NE-300 syringe pump in a $40 \mathrm{~cm}^{3} \mathrm{~min}^{-1}$ flow of $\mathrm{N}_{2}\left(4.4\right.$ mol\% of ethanol in $\left.\mathrm{N}_{2}\right)$. The tests were carried out at atmospheric pressure, WHSV $=1.1 \mathrm{~h}^{-1}$. Temperature was varied stepwise in the range from 205 to $310^{\circ} \mathrm{C}$ by steps of $35^{\circ} \mathrm{C}$. One step consisted of (i) heating ramp $\left(5^{\circ} \mathrm{C}\right.$ $\mathrm{min}^{-1}$ ) and stabilization at the set temperature $(21 \mathrm{~min})$ and (ii) steady temperature state (56 min). The analysis of the effluent gas was carried out by a VARIAN 3800 Gas Chromatograph (8 injections at each temperature) equipped with a flame ionization detector (FID) and a Cydex B column ( $25 \mathrm{~m}$ long, internal diameter $0.22 \mathrm{~mm}$, film thickness $0.25 \mu \mathrm{m}$ ).

\section{Results and discussion}

Hybrid aluminosilicate samples were prepared by NHSG with a nominal Si:Al ratio of 16 . Various organic groups were introduced (see Chart 1), keeping the degree of functionalization constant: one Si atom out of 16 is bonded to an organic moiety that is either terminal (p_PhCH $\mathbf{p}_{\mathbf{2}} \mathbf{p} \mathbf{p} \mathbf{M e}$ ) or bridging $\left(\mathbf{b}_{-} \mathbf{C H}_{\mathbf{2}}, \mathbf{b}_{-} \mathbf{C}_{\mathbf{2}} \mathbf{H}_{4}, \mathbf{b} \_\mathbf{X y}\right)$. NHSG is known to 
produce mixed metal oxides with high homogeneity of metal mixing and good textural properties (even without requiring the use of a sacrificial templating agent). ${ }^{23,24,46}$ Here, the synthetic procedure is based on the alkyl halide elimination (ether route, Eqn. 1). Different silicon precursors with covalently bound organic groups were used in the synthesis in order to incorporate various organic groups into the aluminosilicate matrices: benzyltrichlorosilane, methyltrichlorosilane, bis(trichlorosilyl)methane, 1,2bis(trichlorosilyl)ethane, and 1,4- bis(trichlorosilylmethyl)benzene. ${ }^{7,47}$ The direct Si-Caromatic bond was avoided due to its low hydrothermal gas phase stability in aluminosilicates. ${ }^{27}$

The calcination temperature $\left(300^{\circ} \mathrm{C}\right)$ was chosen so as to eliminate/oxidize a major part of uncondensed isopropoxy groups coming from the sol-gel preparation while preserving the modifying organic moieties bonded via direct $\mathrm{Si}-\mathrm{C}$ bonds as confirmed by TG analyses (Table 1S, Fig. 2S). The first mass loss (up to $300^{\circ} \mathrm{C}$ ) could be attributed to the evaporation of adsorbed water, the organic groups then oxidized between $350{ }^{\circ} \mathrm{C}$ and $700{ }^{\circ} \mathrm{C}$. The theoretical and experimental mass losses for samples containing bulky organic groups (p_PhCH 2 and b_Xy) appeared to be in good agreement (10.3 vs. $10.2 \%$ and 8.2 vs. $8.9 \%$, respectively). However, it should be considered that some residual isopropoxy groups were still present in the samples and burned in this temperature range as well, meaning that the actual contribution of the organic groups is probably lower (see below with NMR quantification). In fact, the pristine sample 16Si-1Al displayed a mass loss of $5.1 \%$ (no mass loss should be observed for this sample in an ideal case).

The samples with different organic groups were almost identical in terms of their textural properties (Fig. 1, Table 2). Specific surface area ranged from 230 to $250 \mathrm{~m}^{2} \mathrm{~g}^{-1}$, total pore volume from 0.60 to $0.77 \mathrm{~cm}^{3} \mathrm{~g}^{-1}$, and average pore size from 9.6 to $12 \mathrm{~nm}$. The isotherm 
shapes (indicating a high proportion of interparticle voids in total porosity ${ }^{48}$ ) were very similar to earlier reported methylated aluminosilicates prepared by the same procedure and slightly lower than pure inorganic benchmark aluminosilicate 16Si-1Al. On one hand the specific surface area decreased only slightly upon organic groups introduction, on the other hand the total pore volume decreased more markedly (Table 2, Fig. 1). ${ }^{12}$

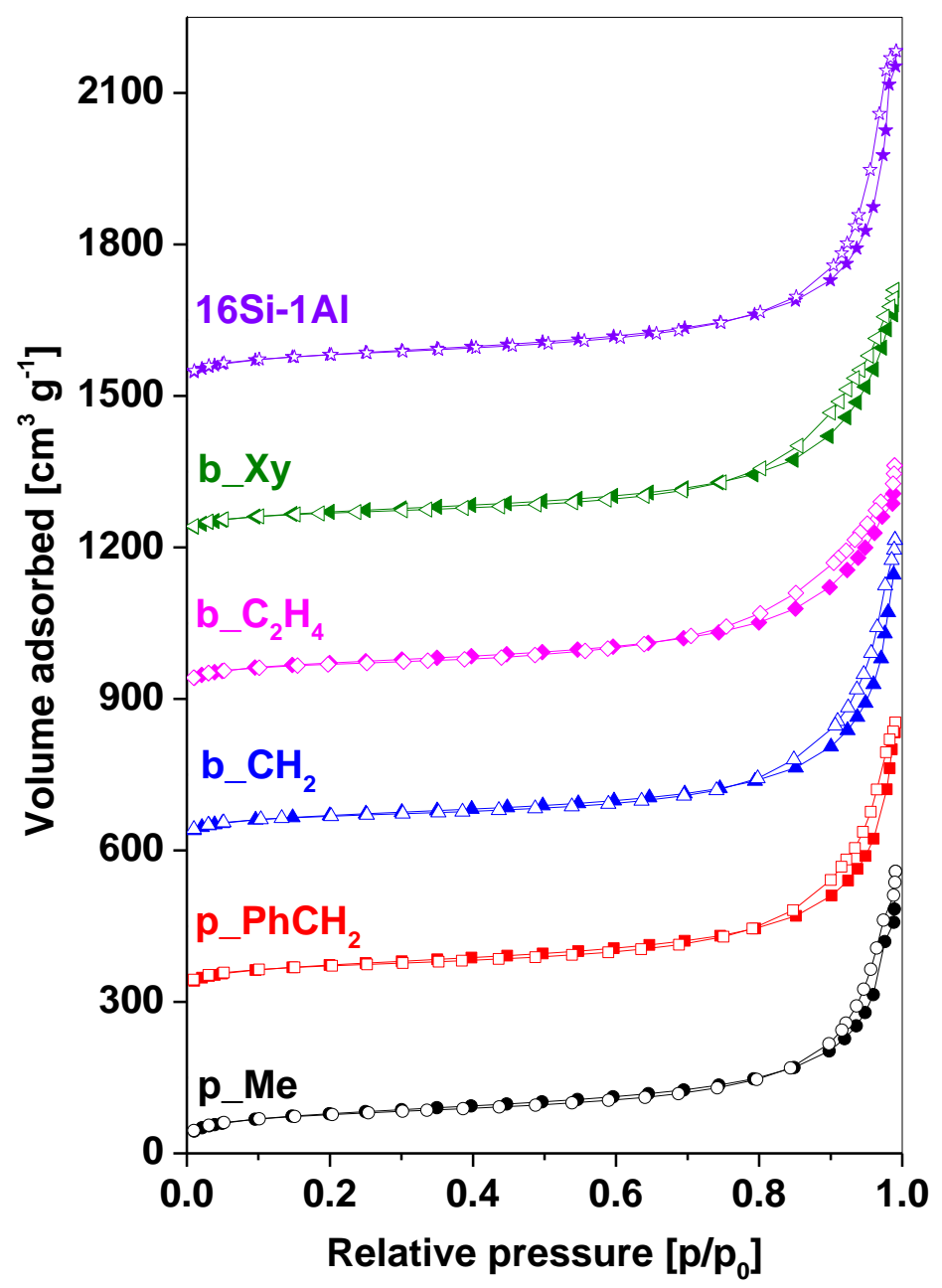

Fig. 1: $\mathrm{N}_{2}$ physisorption measurements performed on aluminosilicate samples with different organic groups and inorganic benchmark 16Si-1Al. Empty symbols are used for the desorption isotherms. The offset between the isotherms equals 300 units in each case.

Table 2: Textural properties of NHSG prepared hybrid aluminosilicate samples containing different organic groups.

\begin{tabular}{|l|l|l|l|}
\hline Sample & SA BET $_{\text {total }}$ & V & D \\
\hline
\end{tabular}




\begin{tabular}{|l|l|l|l|}
\hline & $\left(\mathrm{m}^{2} \mathrm{~g}^{-1}\right)$ & $\left(\mathrm{cm}^{3} \mathrm{~g}^{-1}\right)$ & $(\mathrm{nm})$ \\
\hline p_Me & 270 & 0.75 & 11 \\
\hline p_PhCH & & & \\
\hline b_CH 2 & 250 & 0.77 & 12 \\
\hline b_C2 $\mathrm{H}_{4}$ & 240 & 0.73 & 12 \\
\hline b_Xy & 250 & 0.60 & 9.6 \\
\hline 16Si-1Al & 250 & 0.71 & 12 \\
\hline
\end{tabular}

Samples with different organic groups were analyzed by IR and NMR spectroscopy. IR spectra (Fig. 3S) of all samples were very similar with the main absorption bands originating from vibrations of aluminosilicate matrix. The most intense absorption band at $1050-1065 \mathrm{~cm}^{-1}$ was ascribed to the asymmetric stretching vibration of $\mathrm{Si}-\mathrm{O}-\mathrm{Si}$. The position of this band, at a lower wavenumber in comparison to pure silica $\left(1200 \mathrm{~cm}^{-1}\right)$, is explained by the presence of $\mathrm{Si}-\mathrm{O}-\mathrm{Al}$ bridges. ${ }^{49-51}$ Other absorption bands of lower intensity were observed at 570-580, 798-805, and $925-955 \mathrm{~cm}^{-1}$ and can be assigned to $\mathrm{Si}-\mathrm{O}-\mathrm{Si}$ deformation vibration, symmetric $\mathrm{Si}-\mathrm{O}-\mathrm{Si}$ stretching vibration, and $\mathrm{Si}-\mathrm{O}-\mathrm{H}$ stretching vibration, respectively. ${ }^{52}$ IR spectra did not allow distinguishing the incorporation of the various organic groups due to their low content in the hybrid aluminosilicate catalysts.

On the contrary, SS NMR spectroscopy allowed highlighting the presence of organic groups and verifying their nature. ${ }^{29} \mathrm{Si}$ CPMAS NMR spectra of all samples displayed a main broad signal at $-101 \mathrm{ppm}(\mathrm{Q} 2, \mathrm{Q} 3$, and Q4 sites found respectively at $-92 \mathrm{ppm},-101 \mathrm{ppm}$ and $109 \mathrm{ppm}$ ) accompanied by a minor signal in the range from -45 to $-80 \mathrm{ppm}$ confirming presence of $\mathrm{T}$ species $\left(\mathrm{CSiO}_{3}\right.$ ) (Fig. 2). ${ }^{29} \mathrm{Si} \mathrm{MAS} \mathrm{NMR}$ (no cross-polarization; Fig. 4S) were 
acquired on $\mathbf{p} \_\mathbf{M e}$ and $\mathbf{b} \_\mathbf{C H}_{\mathbf{2}}$ in order to gain an indication on quantity of remaining organic groups (T vs. Q species). Results (Table $1 \mathrm{~S}$ ) must be considered carefully due to a low $\mathrm{RSiO}_{3}$ content and thus a possibly large error during the spectra processing. Nevertheless the P_Me sample showed $55 \%$ of retained organic groups (3.3 at\% experimental vs. 6.02 at\% theoretical). These values were lower in the case of $\mathbf{b} \_\mathbf{C H}_{\mathbf{2}}$ (35\% retained organic groups in comparison to the theoretical value). The rest was probably lost during the calcination step.



Fig. 2: ${ }^{29} \mathrm{Si}$ CPMAS NMR spectra of NHSG prepared aluminosilicate catalysts with different organic groups.

The nature of the organic groups was identified with the help of ${ }^{13} \mathrm{C}$ CPMAS NMR experiments (Fig. 3). Even if the signal to noise ratio is relatively low (due to the low degree of functionalization), this technique unambiguously allowed to prove that the organic groups bound to the silane precursors used in the synthesis were successfully incorporated within the aluminosilicate matrices and were not subject to any change along the different steps of preparation (solvothermal synthesis, drying, and calcination at $300^{\circ} \mathrm{C}$ ). The methyl groups in 
sample $\mathbf{p} \_\mathbf{M e}$ were observed at $-5 \mathrm{ppm}$. The benzyl groups in sample $\mathbf{p} \_\mathbf{P h} \mathbf{C H}_{\mathbf{2}}$ provided two signals at $22 \mathrm{ppm}\left(\mathrm{C}_{6} \mathrm{H}_{5} \mathrm{CH}_{2}\right)$ and $128 \mathrm{ppm}\left(\mathrm{C}_{6} \mathrm{H}_{5} \mathrm{CH}_{2}\right)$. Similarly, the xylylene groups in b_Xy showed the expected peaks at $19 \mathrm{ppm}$ and $128 \mathrm{ppm} .^{27,39}$ The methylene and ethylene groups in $\mathbf{b} \_\mathbf{C H}_{\mathbf{2}}$ and $\mathbf{b} \_\mathbf{C}_{\mathbf{2}} \mathbf{H}_{\mathbf{4}}$ were observed at -3 and $5 \mathrm{ppm}$, respectively (Fig. 3 ). ${ }^{15}$

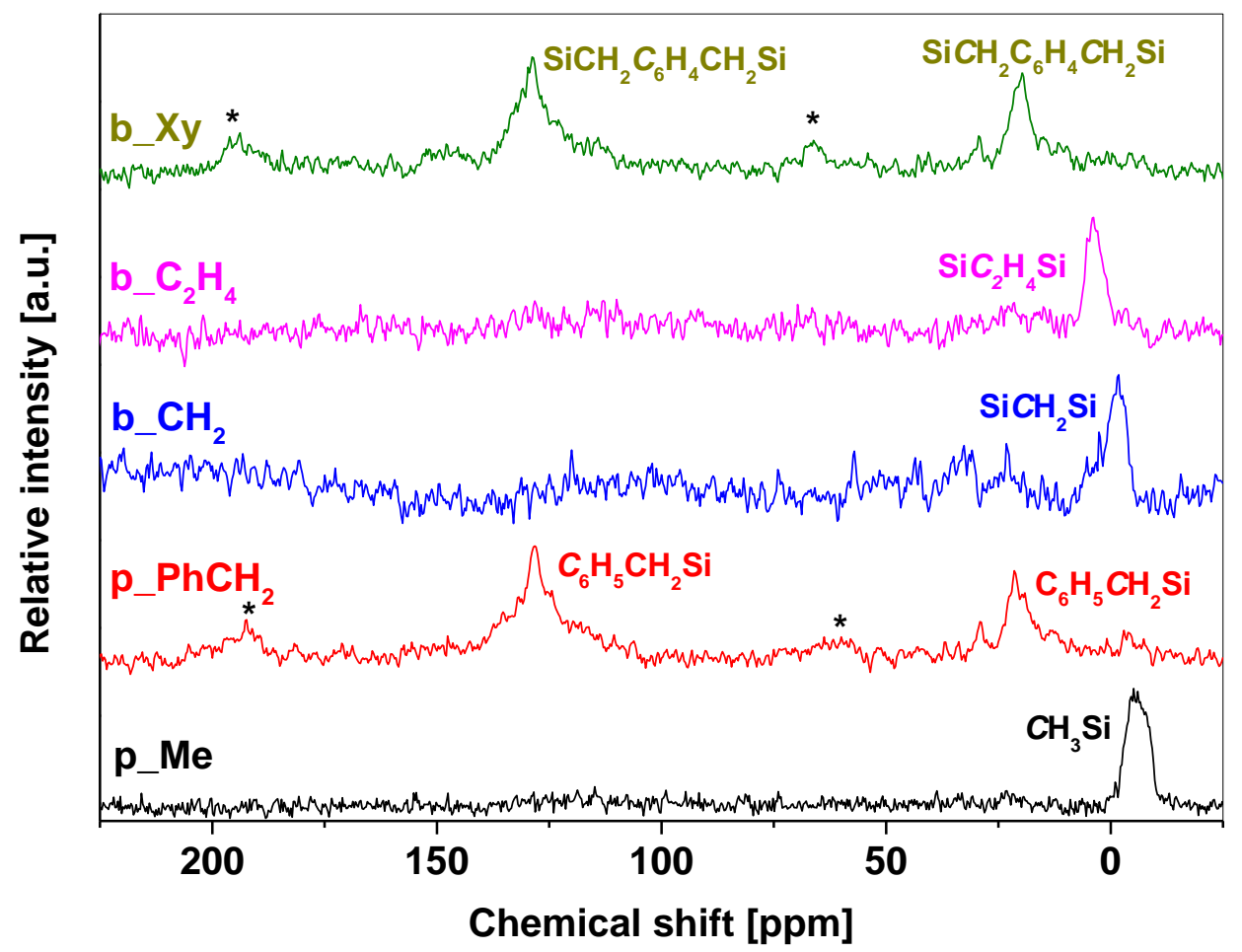

Fig. 3: ${ }^{13} \mathrm{C}$ CPMAS NMR spectra of NHSG prepared aluminosilicate samples with different organic groups. Asterisks denote spinning sidebands.

According to ${ }^{27} \mathrm{Al}$ MAS NMR spectra (Fig. 4) the NHSG prepared samples with different organic groups were very similar - the framework $\mathrm{AlO}_{4}$ species were always present as the most intense peak, $\mathrm{AlO}_{5}$ as a relatively small shoulder, and finally the signal intensities of hexacoordinated Al atoms were also comparable. The ${ }^{27} \mathrm{Al}$ MAS NMR spectra of most of the samples were very similar to earlier reported methylated aluminosilicates and pure inorganic benchmark 16Si-1Al prepared by NHSG (Fig. 4). 

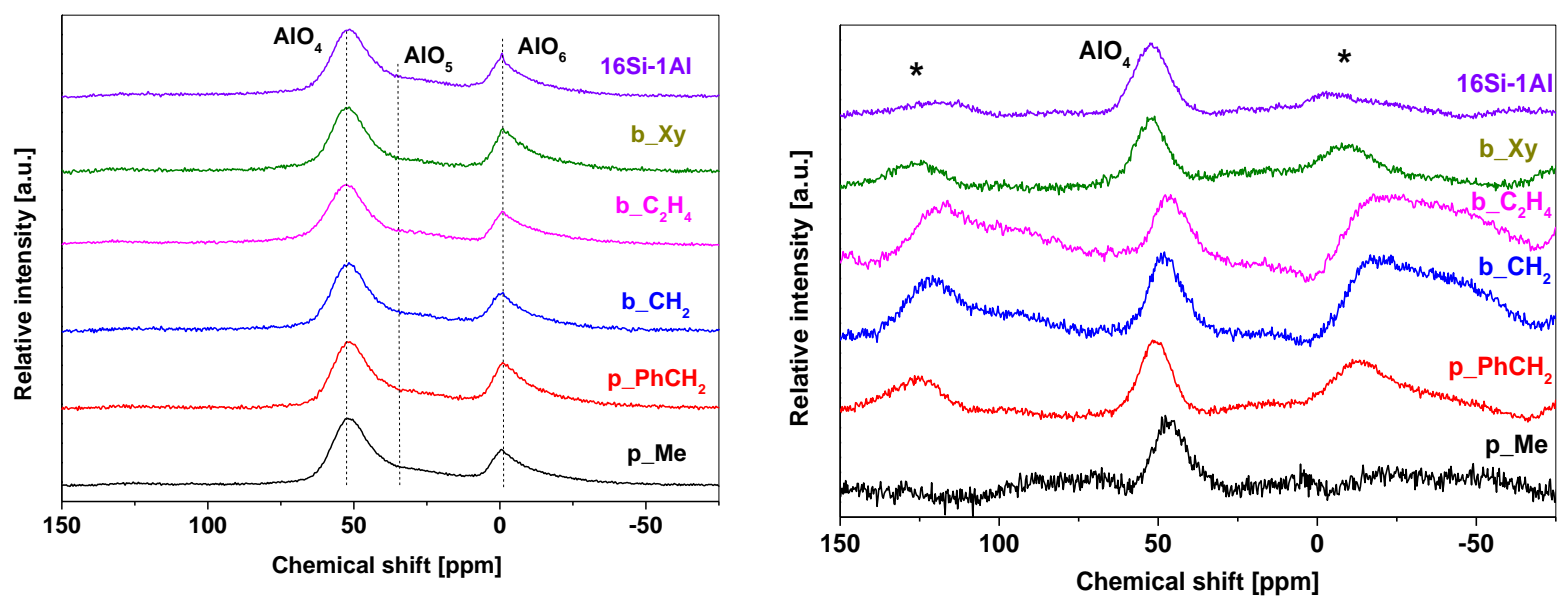

Fig. 4: ${ }^{27} \mathrm{Al}$ MAS NMR spectra of NHSG prepared hybrid aluminosilicate samples with different organic groups. Left: Samples exposed to ambient atmosphere (hydrated); Right: Dehydrated samples with adsorbed pyridine. Asterisks denote spinning sidebands.

To gain a deeper insight into structural motifs present in the catalysts, we performed additional ${ }^{27} \mathrm{Al}$ MAS NMR analyses on dehydrated samples (evacuated at $150^{\circ} \mathrm{C}$, overnight) which were consequently contacted with pyridine. It was found that this treatment led to the complete disappearance of $\mathrm{AlO}_{6}$ and $\mathrm{AlO}_{5}$ species for all hybrid aluminosilicate catalysts and for inorganic benchmark $\mathbf{1 6 S i - 1 A l}$ as well (Fig. 4, right). This behavior indicated that NHSG aluminosilicates with different organic groups did not contain any extra-framework alumina clusters. Octahedrally coordinated Al atoms observed in these samples exposed to ambient atmosphere are in fact isolated Al species able to bind $\mathrm{H}_{2} \mathrm{O}$ molecules from air moisture. ${ }^{18,53,54}$ This again pointed towards the fact that NHSG leads to highly homogeneous Si-Al mixing.

While NMR spectroscopy have shown the successful incorporation of organic groups within the bulk of the samples, XPS and ToF-SIMS provides information on the organic groups present at the catalyst surface. Such information is crucial, considering the decisive role played by the surface in heterogeneous catalysis. In XPS spectra (Fig. 5), all hybrid samples 
exhibited a higher $\mathrm{C}$ content (Table 3 ) in comparison to pristine 16Si-1Al (which only showed the carbon contamination usually encountered in XPS measurement on aluminosilicate materials). The difference was clearly caused by the $\mathrm{C}-(\mathrm{C}, \mathrm{H})$ component of the carbon peak which grew in intensity upon introduction of organic groups. Moreover an aromatic shakeup component was observed for the samples $\mathbf{p} \_\mathbf{P h C H} \mathbf{C H}_{\mathbf{2}}$ and $\mathbf{b} \_\mathbf{X} \mathbf{y}$ evidencing the successful incorporation of aromatic moieties. The contribution of the other oxidized carbon types (C(O), $\mathrm{C}=\mathrm{O}$, and $\mathrm{COO}$ ) typically found in carbon contamination remained fairly constant (1.803.78 at\%; Fig. 5, Table 3). Thus, the presence of the organic moieties at the surface of the hybrid catalysts is confirmed. 


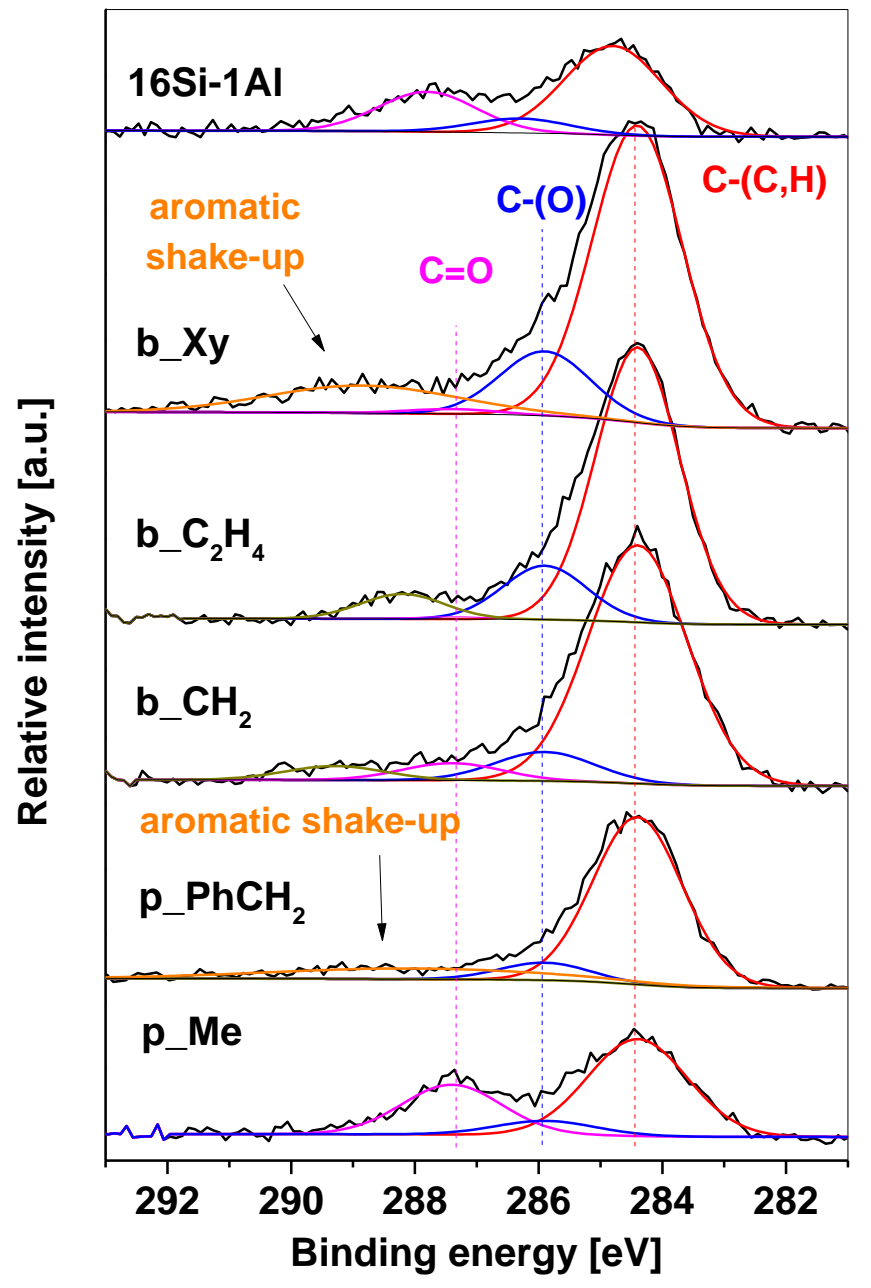

Fig. 5: XPS spectra (C 1s) of NHSG prepared hybrid aluminosilicates with various organic groups. C$(\mathrm{C}, \mathrm{H})$ contribution (at $284.4 \mathrm{eV}$ for hybrid samples and $284.8 \mathrm{eV}$ for pristine sample) is depicted in a red color. $\mathrm{C}-(\mathrm{O})$ component (binding energy higher by $1.5 \mathrm{eV}$ ) is displayed in blue, $\mathrm{C}=\mathrm{O}$ (binding energy higher by $3 \mathrm{eV}$ ) in pink, and $\mathrm{COO}$ in brown. The aromatic shake-up (a broad component shifted by $4-5 \mathrm{eV}$ from the $\mathrm{C}-(\mathrm{C}, \mathrm{H})$ contribution) is shown in orange.

Table 3: Carbon contents in NHSG prepared hybrid aluminosilicate catalysts from XPS data.

\begin{tabular}{|l|c|c|c|}
\hline Sample & $\begin{array}{c}\text { C content total } \\
\text { (at\%) }\end{array}$ & $\begin{array}{c}\text { C-(C,H) content } \\
\text { (at\%) }\end{array}$ & $\begin{array}{c}\text { C aromatic shake-up } \\
\text { (at\%) }\end{array}$ \\
\hline p_Me & 5.9 & 3.6 & - \\
\hline p_PhCH 2 & 15.5 & 11.9 & 2.4 \\
\hline b_CH 2 & 13.8 & 11.0 & - \\
\hline b_C ${ }_{2} \mathrm{H}_{4}$ & 13.7 & 10.5 & - \\
\hline
\end{tabular}




\begin{tabular}{|l|c|c|c|}
\hline b_Xy & 12.3 & 8.6 & 1.7 \\
\hline $16 \mathrm{Si}-\left.1 \mathrm{~A}\right|^{12}$ & 4.7 & 2.9 & - \\
\hline
\end{tabular}

The introduction of organic groups was further studied by ToF-SIMS. Peaks of $\mathrm{C}_{6} \mathrm{H}_{5}{ }^{+}$and $\mathrm{C}_{4} \mathrm{H}_{3}{ }^{+}$(at $\mathrm{m} / \mathrm{z} 77.037$ and 51.026, respectively) indicate the presence of aromatic organic groups at the outermost surface of the catalysts (relevant for $\mathbf{p} \_\mathbf{P h C H} \mathbf{2}$ and $\mathbf{b} \_\mathbf{X y}$; Fig. 6a left and Fig. 5S) and peaks of $\mathrm{CH}_{2}{ }^{+}$and $\mathrm{SiCH}_{2}{ }^{+}$(at $\mathrm{m} / \mathrm{z}=14.015$ and 41.986) can be used as an indication of presence of $\mathrm{Si}-\mathrm{CH}_{2}$ moieties (relevant for all hybrid aluminosilicate catalyts; Fig. $6 \mathrm{~S} r$ and $7 \mathrm{~S}$ ). On one hand, the relative peak areas (normalized per total counts in mass spectra) of $\mathrm{C}_{6} \mathrm{H}_{5}{ }^{+}$and $\mathrm{C}_{4} \mathrm{H}_{3}{ }^{+}$clearly confirmed the presence of aromatic groups (benzyl and xylylene) in the outermost surface layer of $\mathbf{p} \_\mathbf{P h C H}_{\mathbf{2}}$ and $\mathbf{b} \_\mathbf{X y}$ (Fig. 6a, Fig. 5S). On the other hand, the comparison of relative peak areas of $\mathrm{CH}_{2}{ }^{+}$and $\mathrm{SiCH}_{2}{ }^{+}$in hybrid samples and $16 \mathrm{Si}$ 1Al does not allow to confirm the presence of organic groups in the outermost surface layer of hybrid samples as the values fluctuate without any clear trend (Fig. 6S and 7S). This is probably due to a high background originating from the carbon contamination. 
$\mathrm{C}_{6} \mathrm{H}_{5}{ }^{+}$normalized per total counts

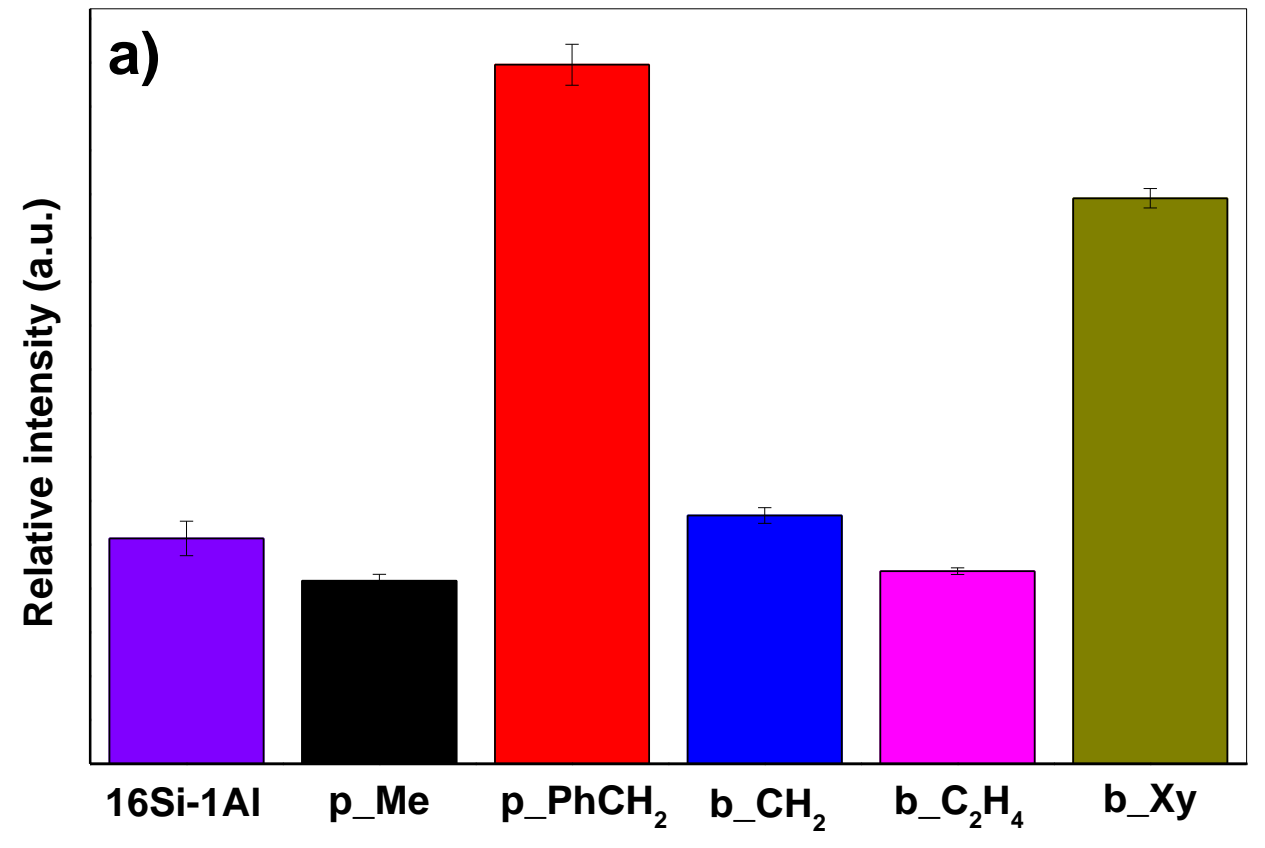

$\mathrm{AlO}_{2}^{-}$normalized per total counts

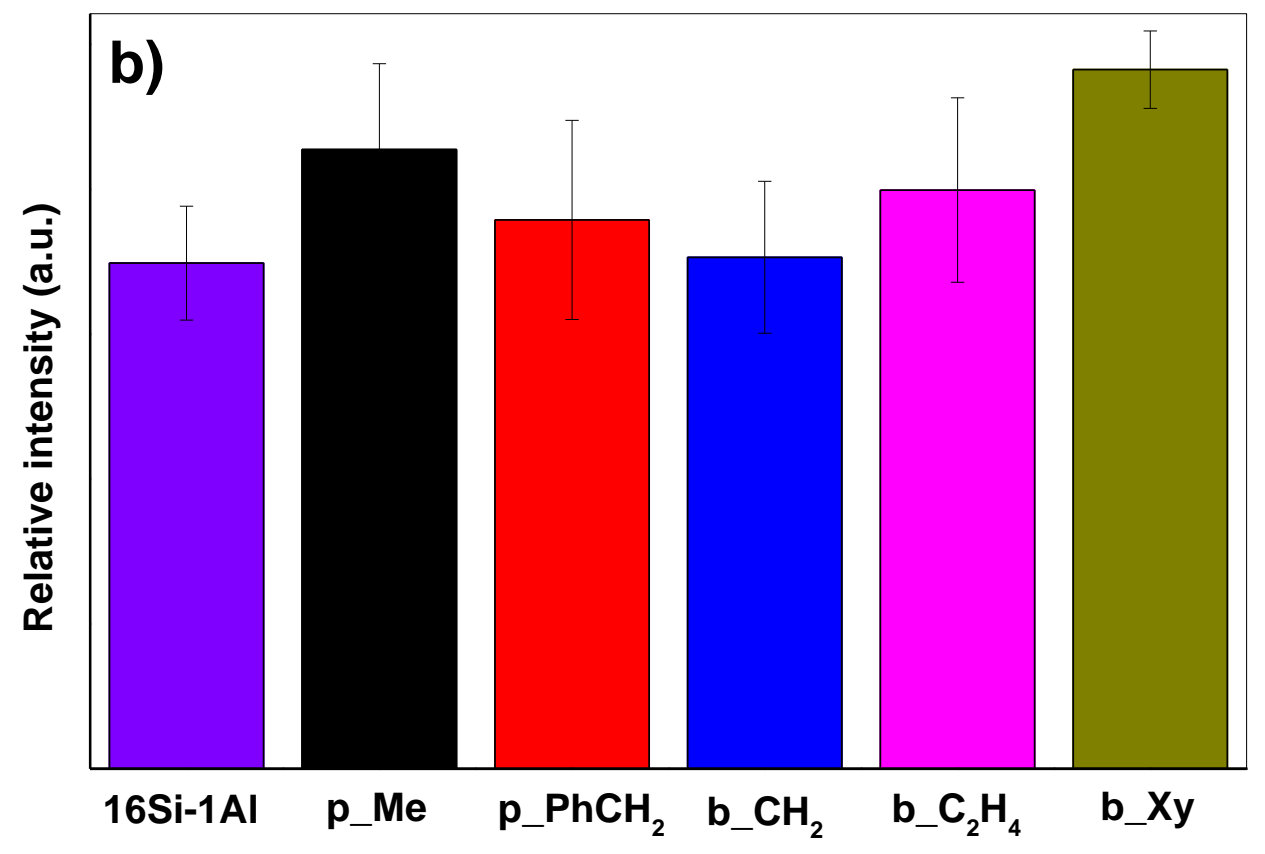




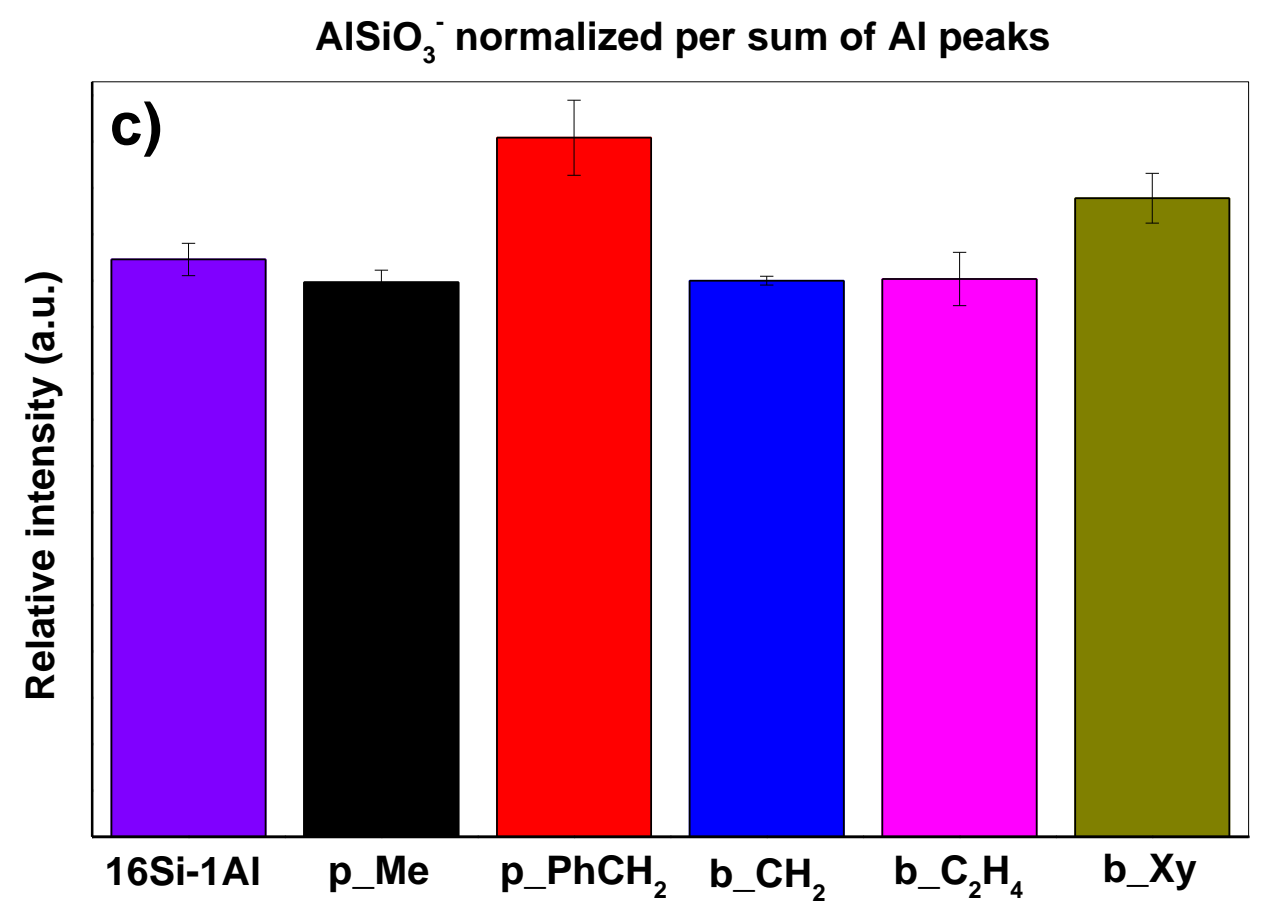

$\mathrm{Al}_{2} \mathrm{O}_{4}^{-}$normalized per sum of $\mathrm{Al}$ peaks

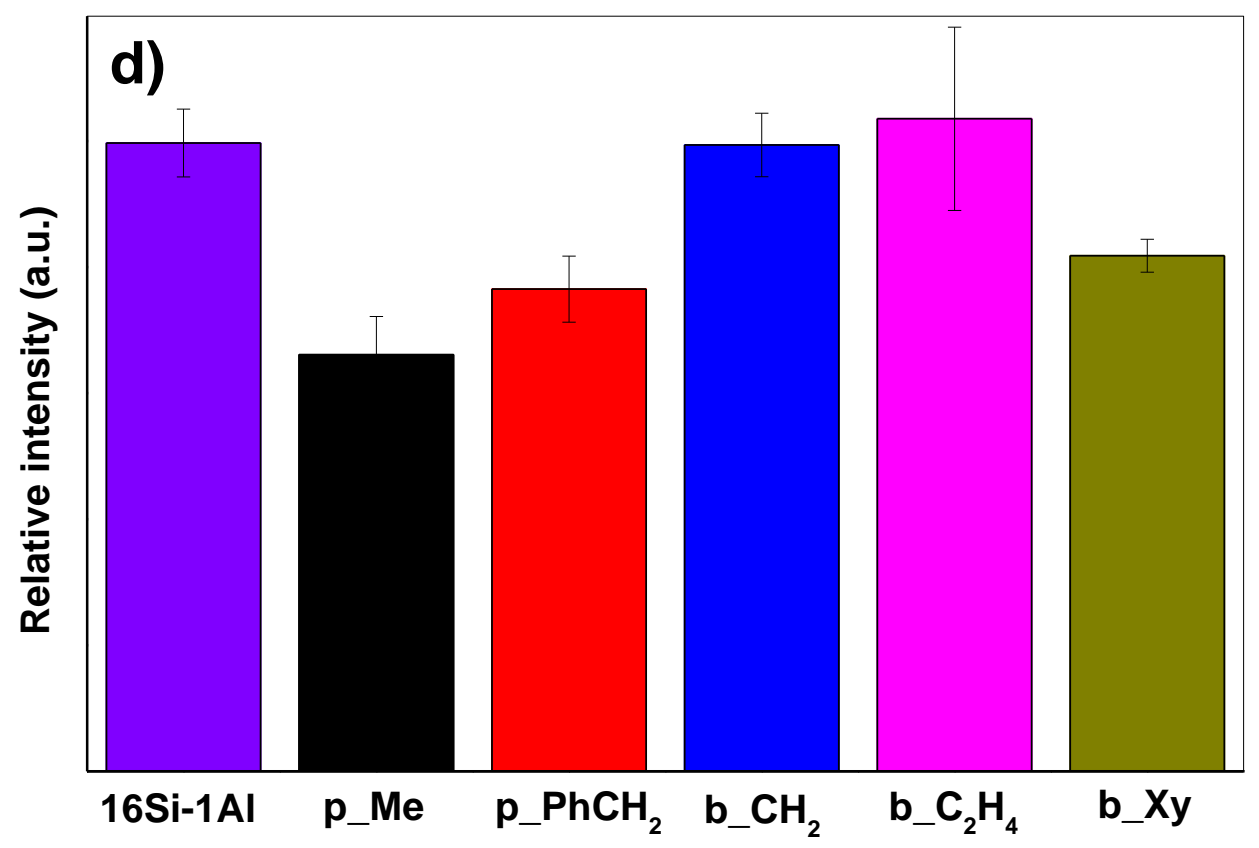

Fig. 6: Comparison of samples with different organic groups in terms of relative peak areas of masses corresponding to a) $\mathrm{C}_{6} \mathrm{H}_{5}{ }^{+}$ions, b) $\mathrm{AlO}_{2}{ }^{-}$ions, c) $\mathrm{AlSiO}_{3}{ }^{-}$ions (mixed Al-Si clusters), and d) $\mathrm{Al}_{2} \mathrm{O}_{4}^{-}$ions ("alumina" clusters) in mass spectra obtained by ToF-SIMS. 
The ToF-SIMS was further used to study the homogeneity of Al mixing within silica matrices. Peaks of $\left(\mathrm{AlSiO}_{3}\right)^{-},\left(\mathrm{AlSi}_{2} \mathrm{O}_{5}\right)^{-},\left(\mathrm{Al}_{2} \mathrm{O}_{4}\right)^{-}$, and $\left(\mathrm{AlO}_{2}\right)^{-}$were followed at $\mathrm{m} / \mathrm{z}=102.94,162.92$, 117.95, and 58.967, respectively. These signals were well resolved, without any overlap, and undoubtedly assigned. The peak area of $\left(\mathrm{AlSiO}_{3}\right)^{-}$and $\left(\mathrm{AlSi}_{2} \mathrm{O}_{5}\right)^{-}$is taken as an indication of the presence of Al species incorporated in the silica matrix (which can be associated with homogeneity of the aluminosilicate catalysts). The peak area of $\left(\mathrm{Al}_{2} \mathrm{O}_{4}\right)^{-}$is taken as an indication of the presence of alumina clusters (poorly dispersed Al oxide species). Finally the peak area of $\left(\mathrm{AlO}_{2}\right)^{-}$is a function of $\mathrm{Al}$ concentration in the surface layer and serves as a benchmark. Clearly, all hybrid samples displayed a similar or higher concentration of $\left(\mathrm{AlO}_{2}\right)^{-}$ in comparison to pristine 16Si-1Al sample (Fig. 6b). Thus, it can be suggested that hybrid samples possessed at least the same surface Al concentration than 16Si-1Al. This fact is in agreement with XPS data, where Si/AI ratios for all hybrid samples were lower than for pristine catalyst (Table 1).

Reporting the peak areas of the mixed Al-Si ions vs. the sum of these four peaks containing Al (Fig. 6c, Fig. 8S) it appears that the samples containing aromatic organic groups (p_PhCH and $\mathbf{b} \_\mathbf{X y}$ ) display a higher proportion of mixed clusters in comparison to other samples (including the inorganic benchmark 16Si-1Al). The opposite trend was obtained for $\left(\mathrm{Al}_{2} \mathrm{O}_{4}\right)^{-}$ peak areas: samples with aromatic organic groups displayed a lower amount of alumina clusters per aluminum atoms in the surface layer in comparison to other hybrid samples (Fig. $6 \mathrm{~d})$. Thus, the homogeneity of Si-Al mixing appears to be slightly improved in the case of P_PhCH $\mathbf{P}_{\mathbf{2}}$ and $\mathbf{b} \_\mathbf{X y}$ samples; the other catalysts seem to display a similar Si-Al dispersion to 16Si-1Al benchmark sample. Importantly, the quality of the Si-Al mixing appears to be at 
least as good in the hybrid samples as in the inorganic benchmark, showing that the introduction of organic moieties did not deteriorate the homogeneity of the metallosilicate, which is a decisive advantage of NHSG. Overall, the ToF-SIMS analyses of NHSG prepared hybrid aluminosilicate catalysts showed a similar or higher surface Al concentration and similar or higher Si-Al mixing homogeneity in comparison to pristine 16Si-1Al sample.

The number of acid sites (determined by IR spectroscopy combined with pyridine adsorption) in hybrid aluminosilicate catalysts ranged between 0.028 and $0.038 \mathrm{mmol} \mathrm{g}{ }^{-1}$ (Table 4, Fig. 9S and 10S). The pristine sample 16Si-Al was the least acidic $\left(0.027 \mathrm{mmol} \mathrm{g}^{-1}\right)$. Moreover, samples containing aromatic organic groups exhibited somewhat higher numbers, while catalysts with aliphatic groups displayed lower quantity of acid sites. These results are in a good agreement with XPS and ToF-SIMS analyses: the hybrid samples showed a higher surface Al concentration, aluminosilicate catalysts containing aromatic groups displayed more homogeneous Si-Al dispersion and, consequently, all hybrid samples possessed higher acid site numbers than pristine catalyst with the maxima observed for P_PhCH 2 and b_Xy.

Table 4: Results of IR spectroscopy combined with pyridine adsorption performed on hybrid aluminosilicates containing different organic groups.

\begin{tabular}{|c|c|c|c|c|}
\hline Sample & $\begin{array}{c}\text { Total acid } \\
\text { sites } \\
\left(\mathrm{mmol} \mathrm{g}^{-1}\right)\end{array}$ & $\begin{array}{c}\text { B/L } \\
\text { ratio } \\
(-)\end{array}$ & $\begin{array}{c}\text { Acid sites after } \\
\text { desorption at } \\
350{ }^{\circ} \mathrm{C}(\%)\end{array}$ & $\begin{array}{c}\text { B/L ratio after } \\
\text { desorption at } 350 \\
{ }^{\circ} \mathrm{C}(-)\end{array}$ \\
\hline p_Me & 0.035 & 0.40 & 70 & 0.16 \\
\hline P_PhCH 2 & 0.049 & 0.37 & 73 & 0.20 \\
\hline b_C $2 \mathrm{H}_{4}$ & 0.036 & 0.36 & 63 & 0.13 \\
\hline b_Xy & 0.045 & 0.29 & 58 & 0.13 \\
\hline
\end{tabular}




\begin{tabular}{|c|c|c|c|c|}
\hline 16Si-1Al & 0.035 & 0.83 & 72 & 0.17 \\
\hline p_PhCH $2-500$ & 0.090 & 0.22 & 65 & 0.04 \\
\hline 16Si-1Al-500 & 0.059 & 0.83 & 65 & 0.21 \\
\hline
\end{tabular}

Both Brønsted and Lewis acid sites are present in hybrid aluminosilicates prepared by NHSG.

The $\mathrm{Br} \varnothing$ nsted-to-Lewis (B/L) ratio ranges from 0.29 to 0.37 indicating similar representation among the samples (Table 4). Brønsted acid sites display lower strength in comparison to Lewis acid sites; indeed, the $\mathrm{B} / \mathrm{L}$ ratio decreases in all cases upon evacuation at $350^{\circ} \mathrm{C}$. The acid site strength is also similar among the samples with different organic groups: in all samples, a relatively high fraction of pyridine (58-73\%) stays adsorbed at the acid sites after evacuation.

While the acid site strength in the fully inorganic 16Si-1Al catalyst lies within the range of acid site strengths in hybrid aluminosilicates, the $\mathrm{B} / \mathrm{L}$ ratio is substantially higher in $16 \mathrm{Si}-1 \mathrm{Al}$ catalyst (0.83) than in all hybrid catalysts (Table 4). This effect has already been observed in the case of methylated aluminosilicates prepared by NHSG, ${ }^{12}$ and explained with the help of IR spectroscopy: Brønsted acidity in amorphous aluminosilicates is known to originate from pseudo-bridging Si-OH...Al bridges, where Al atom has to act as a Lewis acid. ${ }^{55-57}$ Therefore the substitution of $\mathrm{Si}-\mathrm{OH}$ groups with $\mathrm{Si}-\mathrm{R}$ moieties leads to a lower $\mathrm{B} / \mathrm{L}$ ratio in the case of hybrid aluminosilicates.

Water adsorption was investigated on hybrid aluminosilicates to probe their hydrophilic/hydrophobic properties (Fig. 7). The shape of the isotherms indicated no marked change in surface hydrophilicity upon various organic groups introduction: the isotherms always started with a steep increase at the low $\mathrm{p} / \mathrm{p}_{0}$ and copied the shape of $\mathrm{N}_{2}$ adsorption 
isotherms in all cases. As suggested in the literature, $, 943,44$ a measure of hydrophilicity can be obtained from $\mathrm{H}_{2} \mathrm{O}$ and $\mathrm{N}_{2}$ sorption data by comparing the volume of adsorbed $\mathrm{H}_{2} \mathrm{O}$ to the volume of adsorbed $\mathrm{N}_{2}$ at given $\mathrm{p} / \mathrm{p}_{0}$ values (both adsorbates being considered as in liquid phase). This "hydrophilicity index" is here calculated and reported in $\mathrm{p} / \mathrm{p}_{0}$ range from 0 to 0.5 (noted " $\mathrm{X}_{\mathrm{p} / \mathrm{p} 0 \text { "; }}$ Fig. 11S). Such ratio is here fully relevant since the texture of the materials is similar in all cases. The hydrophilicity index at $p / p_{0}=0.3 \mathrm{~s}$ reported in Fig. 7 for each catalyst. The value ranges from 32 to $47 \%$ only and is very similar to $\mathrm{X}_{0.3}$ of pristine sample 16Si-1Al (39\%) indicating only minor changes in hydrophilicity upon organic groups introduction, similar to our previous report on methylated aluminosilicates ${ }^{12}$ 

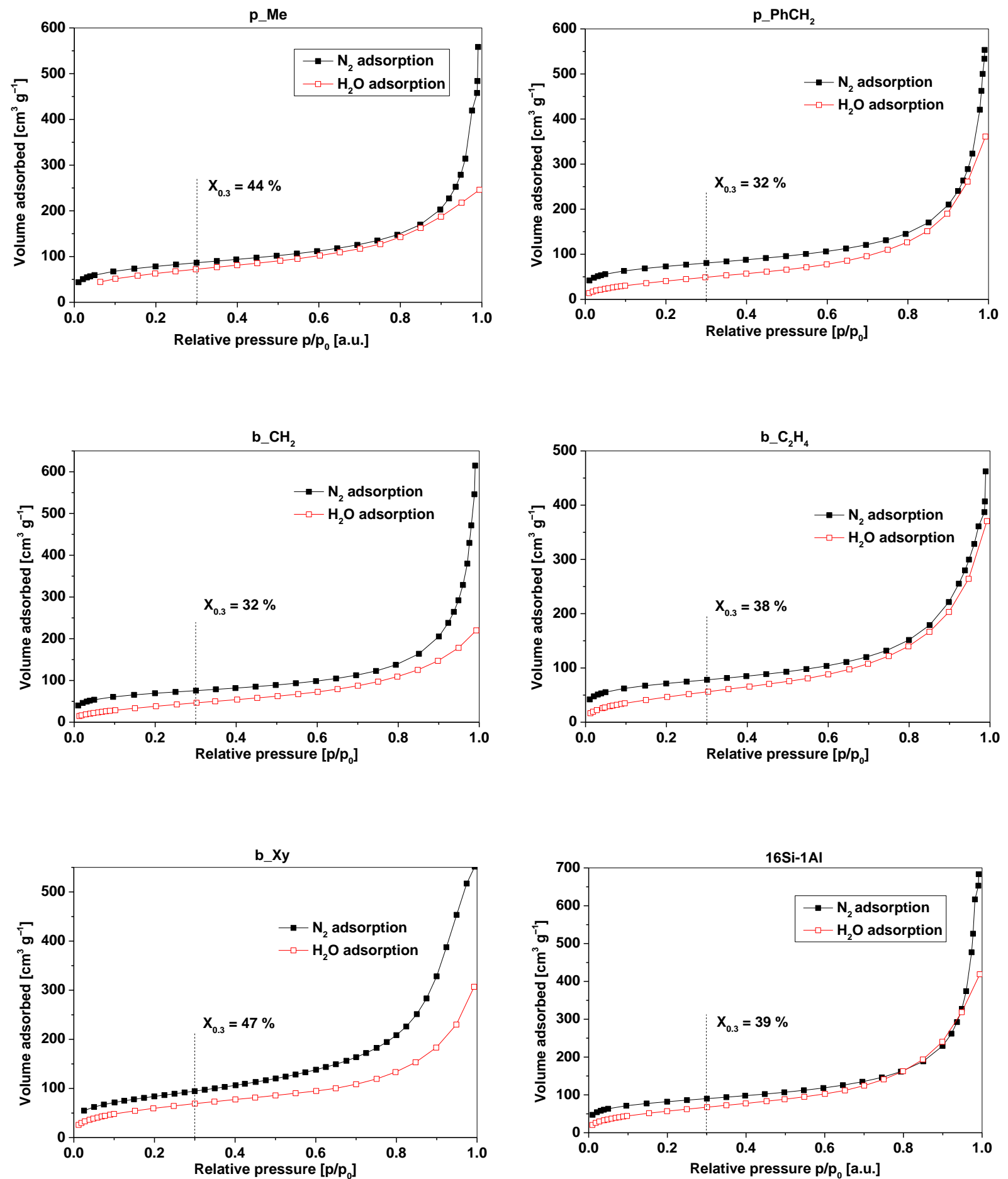

Fig. 7: Comparison of $\mathrm{N}_{2}$ (solid symbols) and $\mathrm{H}_{2} \mathrm{O}$ (open symbols) adsorption isotherms for NHSG prepared aluminosilicates with various organic groups. "Hydrophilicity index “ $\mathrm{X}_{0.3}$ was calculated as a ratio of volume of adsorbed liquid $\mathrm{H}_{2} \mathrm{O}$ and volume of adsorbed liquid $\mathrm{N}_{2}$ at $0.3 \mathrm{p} / \mathrm{p}_{0}{ }^{44}$. 
The water contact angles were recorded in order to complement the water sorption experiments (on samples contacted with ambient air and pelletized). Aluminosilicate catalysts with various organic groups were all found to remain hydrophilic, with water contact angles in the $22-48^{\circ}$ range. Samples $\mathbf{p} \_\mathbf{M e}, \mathbf{b} \_\mathbf{C}_{\mathbf{2}} \mathbf{H}_{\mathbf{4}}$, and $\mathbf{b} \_\mathbf{X} \mathbf{y}$ exhibit very similar water contact angles to pure inorganic benchmark catalyst $16 \mathrm{Si}-1 \mathrm{Al}\left(21.5 \pm 1.7^{\circ}\right)$. Hybrid aluminosilicates $\mathbf{p} \_\mathbf{P h C H}$ and $\mathbf{b} \_\mathbf{C H}_{\mathbf{2}}$ exhibited somewhat higher contact angles indicating lower hydrophilicity $\left(35.3 \pm 4.7\right.$ and $47.6 \pm 4.4^{\circ}$, respectively, Fig. $\left.12 \mathrm{~S}\right)$. Interestingly, these two samples displayed slightly lower hydrophilicity according to "hydrophilicity index" derived from water sorption measurements as well.

Catalytic performance of hybrid samples in the gas phase ethanol dehydration was compared to inorganic benchmark 16Si-1Al (Fig. 8). On the one hand samples containing aromatic organic groups ( $\mathbf{p} \_\mathbf{P h C H} \mathbf{C H}_{\mathbf{2}}$ and $\left.\mathbf{b} \_\mathbf{X} \mathbf{y}\right)$ and $\mathbf{p} \_\mathbf{M e}$ showed higher ethylene yields than 16Si-1Al (Fig. 8). The ethylene yield over $\mathbf{p} \_\mathbf{M e}, \mathbf{p} \_\mathbf{P h C H}_{2}$, and $\mathbf{b} \_\mathbf{X y}$ improved mainly due to markedly higher ethylene selectivity (Fig. 13S, right) in comparison to the inorganic benchmark. The ethanol conversion was slightly higher in samples containing aromatic and pendant methyl groups as well (Fig. 13S, left). On the other hand the catalyst with $\mathrm{SiCH}_{2} \mathrm{CH}_{2} \mathrm{Si}$ (b_ $\mathbf{C}_{2} \mathrm{H}_{4}$ ) groups exhibited worse catalytic performance. The sample with methylene bridges ( $\left(\mathbf{b}_{-} \mathbf{C H}_{\mathbf{2}}\right.$ ) reached a similar ethylene yield to $\mathbf{1 6 S i - 1 \mathrm { Al }}$ (Fig. 8); it was only slightly worse than 16Si-1Al in terms of ethanol conversion (Fig. 13S, left) but exhibited somewhat better ethylene selectivity (Fig. 13S, right). Any direct effect of the presence of organic groups on the catalytic properties (e.g. enhanced water desorption) seems to be unlikely; the catalytic performance showed correlation neither with hydrophilicity indices $\mathrm{X}_{\mathrm{p} / \mathrm{po}}$ nor with water contact angles. Overall, the results obtained for hybrid aluminosilicate catalysts mostly follow the acidic properties: hybrid samples with higher amount of acid sites 
and lower $\mathrm{B} / \mathrm{L}$ ratio perform better (Table 4). The only exception is $\mathbf{b} \_\mathbf{C}_{2} \mathbf{H}_{\mathbf{4}}$ which performs worse than expected on the base of its acidic properties. Finally, the selectivity improvement for $\mathbf{p} \_\mathbf{M e}, \mathbf{p} \_\mathbf{P h C H} \mathbf{C}_{\mathbf{2}}$ and $\mathbf{b} \_\mathbf{X} \mathbf{y}$ might be explained by the marked lowering the $\mathrm{B} / \mathrm{L}$ ratio in the case of the hybrid samples: catalysts with more abundant strong Lewis acid sites have been shown to produce ethylene with higher selectivity. ${ }^{12,38,54,58}$

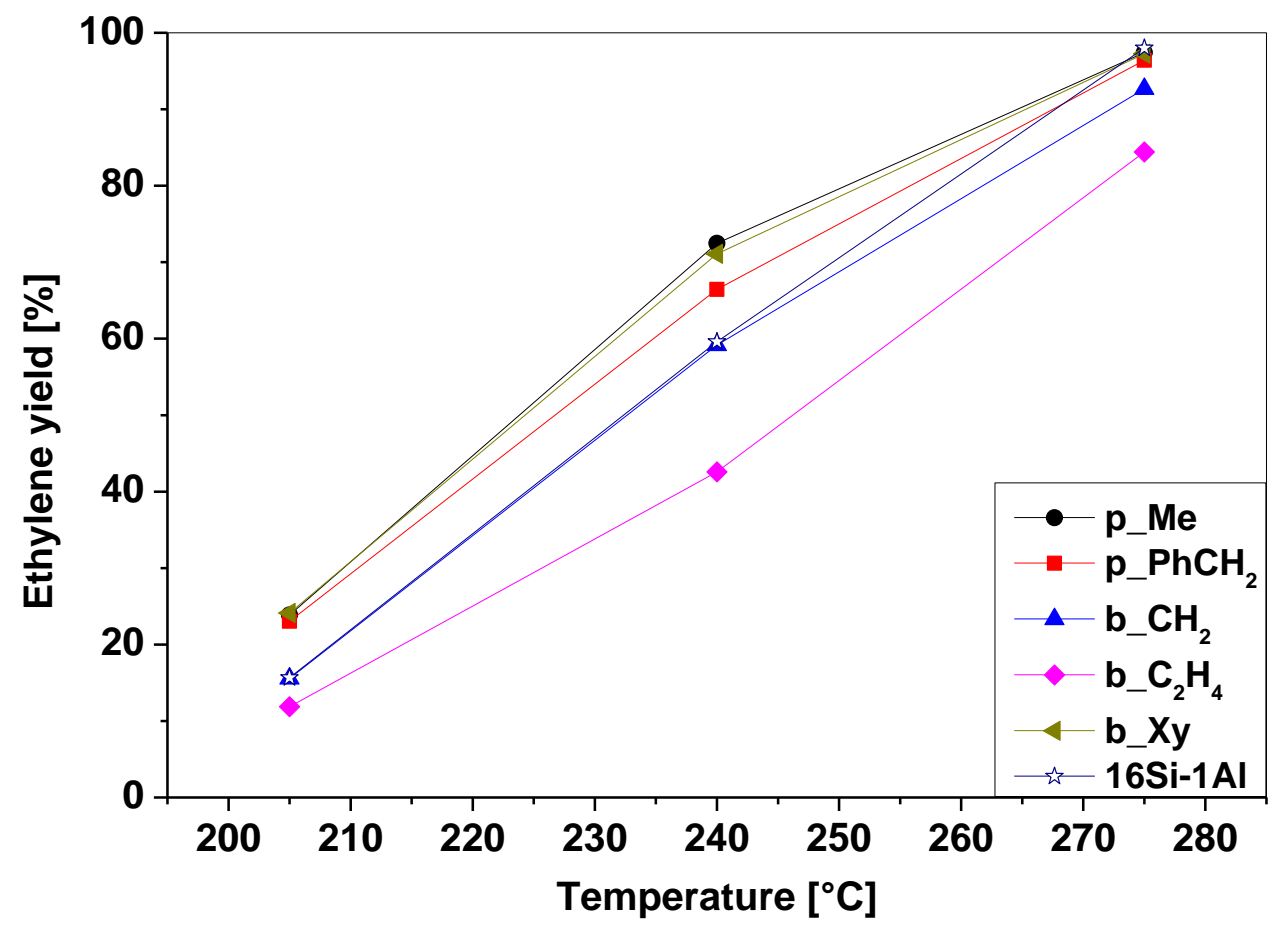

Fig. 8: Ethylene yield in gas phase ethanol dehydration over hybrid aluminosilicate catalysts prepared by NHSG. Black circles denote catalyst $\mathrm{p} \_\mathrm{Me}$, red squares $\mathrm{p}_{-} \mathrm{PhCH}_{2}$, blue triangles (up) b_CH , pink diamonds $b_{-} \mathrm{C}_{2} \mathrm{H}_{4}$, brown triangles (left) b_Xy, and violet stars (empty) denote 16Si-1Al inorganic benchmark.

To confirm that the organic groups presence (hydrophilicity/hydrophobicity) had only negligible direct effect on catalytic performance, $\mathbf{p} \_\mathrm{PhCH}_{2}$ was calcined at $500{ }^{\circ} \mathrm{C}$ in order to completely remove organic groups and the resulting catalyst (p_PhCH $\mathbf{2}-\mathbf{5 0 0}$ ) was tested again in ethanol dehydration. As a reference, 16Si-1Al was also re-calcined and re-tested

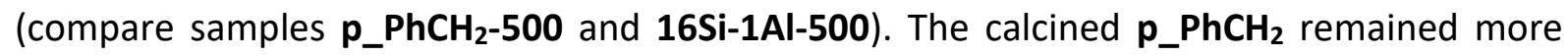
active than the calcined 16Si-1Al (Fig. 14S, left). This agrees with the fact that sample p_PhCH 2 contained more acid sites than $\mathbf{1 6 S i - 1 A l}$ both before and after calcination (Table 4). 
In other words, the organic groups somehow modify the NHSG process - probably owing to a change in the reactivity of the precursors - which directly affects the catalyst properties (homogeneity, amount of surface acid sites), and therefore indirectly affects catalytic performance. On the other hand the ethylene selectivity was very similar for both calcined samples (Fig. 14S, right). This is in agreement with our observation that hybrid samples (before calcination) exhibit a higher ethylene selectivity because of lower B/L ratios. This influence was not observed any more after the organic groups removal by calcination: the Brønsted acid sites can be formed in both calcined samples in situ upon the action of water originating in ethanol dehydration (although the originally hybrid sample $\mathbf{p} \_\mathbf{P h C H}_{\mathbf{2}}-\mathbf{5 0 0}$ still exhibited much lower B/L ratio).

\section{Conclusions}

In summary, we have prepared hybrid aluminosilicates containing various organic groups (pendant benzyl and methyl; bridging methylene, ethylene, and xylylene) prepared by one pot non-hydrolytic sol-gel. The Si:Al ratio was 16 in all samples; one Si atom out of 16 was bound to an organic group (samples contained $15 \mathrm{SiO}_{4}$ units per one $\mathrm{RSiO}_{3}$ group in case of terminal organic groups and $30 \mathrm{SiO}_{4}$ units per one $\mathrm{O}_{3} \mathrm{Si}-\mathrm{R}-\mathrm{SiO}_{3}$ moiety). The presence of organic groups was confirmed by MAS NMR, XPS, and ToF-SIMS analyses. The addition of organic groups did not markedly alter nor the structure (IR, MAS NMR), porosity $\left(\mathrm{N}_{2}\right.$ adsorption-desorption experiments), neither the hydrophilicity (water adsorption and contact angle) of aluminosilicate catalysts. In the contrary, the addition of organic groups induced slight changes in the homogeneity of Si-Al mixing which was studied by ToF-SIMS analyses in the outermost surface layer: the presence of aromatic organic groups seemed to be beneficial and increased the dispersion of Al forming more isolated species. This in turn 
led to variations in the numbers of acid sites: aluminosilicate catalysts containing benzyl and xylylene organic groups exhibited higher acid site numbers, while catalysts with methylene and ethylene bridges showed a lower acid site numbers. This appears to be directly associated with the catalyst activity, as conversion is dictated by the number of acid sites. Finally, the presence of organic groups also influenced Brønsted-to-Lewis ratios: all hybrid catalysts displayed lower $\mathrm{B} / \mathrm{L}$ ratio than pure inorganic $16 \mathrm{Si}-1 \mathrm{Al}$, probably due to a lower $\mathrm{Si}-$ $\mathrm{OH}$ groups content (these were substituted by Si-R groups). This is associated with a higher selectivity for ethylene at the expense of diethylether.

\section{Acknowledgments}

A.S. acknowledges funding from the European Union's Horizon 2020 research and innovation programme under the Marie Skłodowska-Curie grant agreement No 751774. F.R.S.-F.N.R.S. is thanked for the acquisition of the physi-chemisorption equipment (project "EQP U.N030.18"). Authors acknowledge the 'Communauté française de Belgique' for the financial support through the ARC programme (15/20-069). This research used resources of the "Plateforme Technologique Physico-Chemical Characterization" - PC $C^{2}$, the SIAM platform (Synthesis, Irradiation \& Analysis of Materials) and the MORPH-IM platform (Morphology \& Imaging) located at the University of Namur. The work has been financially supported by the Czech Science Foundation under the project GJ20-03636Y. D.P. Debecker thanks the Francqui Foundation for his "Francqui Research Professor" chair. J.F. Statsyns is acknowledged for the technical help. 


\section{References}

(1) Faustini, M.; Nicole, L.; Ruiz-Hitzky, E.; Sanchez, C. History of Organic-Inorganic Hybrid Materials: Prehistory, Art, Science, and Advanced Applications. Adv. Funct. Mater. 2018, 28 (27), 1704158. https://doi.org/10.1002/adfm.201704158.

(2) De Clippel, F.; Dusselier, M.; Van De Vyver, S.; Peng, L.; Jacobs, P. A.; Sels, B. F. Tailoring Nanohybrids and Nanocomposites for Catalytic Applications. Green Chem. 2013, 15 (6), 1398-1430. https://doi.org/10.1039/c3gc37141g.

(3) Bispo, C.; Ferreira, P.; Trouvé, A.; Batonneau-Gener, I.; Liu, F.; Jérôme, F.; Bion, N. Role of Acidity and Hydrophobicity in the Remarkable Catalytic Activity in Water of Sulfonic Acid-Functionalized Phenyl-PMO Materials. Catal. Today 2013, 218-219, 85-92. https://doi.org/10.1016/j.cattod.2013.06.004.

(4) An, S.; Sun, Y.; Song, D.; Zhang, Q.; Guo, Y.; Shang, Q. Arenesulfonic AcidFunctionalized Alkyl-Bridged Organosilica Hollow Nanospheres for Selective Esterification of Glycerol with Lauric Acid to Glycerol Mono- and Dilaurate. J. Catal. 2016, 342, 40-54. https://doi.org/10.1016/j.jcat.2016.07.004.

(5) Sánchez-Vázquez, R.; Pirez, C.; Iglesias, J.; Wilson, K.; Lee, A. F.; Melero, J. A. ZrContaining Hybrid Organic-Inorganic Mesoporous Materials: Hydrophobic Acid Catalysts for Biodiesel Production. ChemCatChem 2013, 5 (4), 994-1001. https://doi.org/10.1002/cctc.201200527.

(6) Smeets, V.; Ben Mustapha, L.; Schnee, J.; Gaigneaux, E. M.; Debecker, D. P. Mesoporous SiO2-TiO2 Epoxidation Catalysts: Tuning Surface Polarity to Improve Performance in the Presence of Water. Mol. Catal. 2018, 452, 123-128. https://doi.org/10.1016/j.mcat.2018.04.011. 
(7) Lorret, O.; Lafond, V.; Mutin, P. H.; Vioux, A. One-Step Synthesis of Mesoporous Hybrid Titania-Silica Xerogels for the Epoxidation of Alkenes. Chem. Mater. 2006, 18 (20), 4707-4709. https://doi.org/10.1021/cm061478q.

(8) Melero, J. A.; van Grieken, R.; Morales, G. Advances in the Synthesis and Catalytic Applications of Organosulfonic-Functionalized Mesostructured Materials. Chem. Rev. 2006, 106 (9), 3790-3812. https://doi.org/10.1021/cr050994h.

(9) Gounder, R.; Davis, M. E. Monosaccharide and Disaccharide Isomerization over Lewis Acid Sites in Hydrophobic and Hydrophilic Molecular Sieves. J. Catal. 2013, 308, 176188. https://doi.org/10.1016/j.jcat.2013.06.016.

(10) Vivian, A.; Fusaro, L.; Debecker, D. P.; Aprile, C. Mesoporous Methyl-Functionalized Sn-Silicates Generated by the Aerosol Process for the Sustainable Production of Ethyl Lactate. ACS Sustain. Chem. Eng. 2018, 6 (11), 14095-14103. https://doi.org/10.1021/acssuschemeng.8b02623.

(11) Silvestre-Alberó, J.; Domine, M. E.; Jordá, J. L.; Navarro, M. T.; Rey, F.; RodríguezReinoso, F.; Corma, A. Spectroscopic, Calorimetric, and Catalytic Evidences of Hydrophobicity on Ti-MCM-41 Silylated Materials for Olefin Epoxidations. Appl. Catal. A Gen. 2015, 507 (SEPTEMBER), 14-25. https://doi.org/10.1016/j.apcata.2015.09.029.

(12) Styskalik, A.; Kordoghli, I.; Poleunis, C.; Delcorte, A.; Moravec, Z.; Simonikova, L.; Kanicky, V.; Aprile, C.; Fusaro, L.; Debecker, D. P. Hybrid Mesoporous Aluminosilicate Catalysts Obtained by Non-Hydrolytic Sol-Gel for Ethanol Dehydration. J. Mater. Chem. A 2020, 8 (44), 23526-23542. https://doi.org/10.1039/d0ta07016e.

(13) Vivian, A.; Soumoy, L.; Fusaro, L.; Fiorilli, S.; Debecker, D. P.; Aprile, C. SurfaceFunctionalized Mesoporous Gallosilicate Catalysts for the Efficient and Sustainable 
Upgrading of Glycerol to Solketal. Green Chem. 2020.

https://doi.org/10.1039/d0gc02562c.

(14) Vriamont, C.; Devillers, M.; Riant, O.; Hermans, S. Catalysis with Gold Complexes Immobilised on Carbon Nanotubes by $\pi-\pi$ Stacking Interactions: Heterogeneous Catalysis versus the Boomerang Effect. Chem. - A Eur. J. 2013, 19 (36), 12009-12017. https://doi.org/10.1002/chem.201300998.

(15) Styskalik, A.; Skoda, D.; Moravec, Z.; Babiak, M.; Barnes, C. E.; Pinkas, J. Control of Micro/Mesoporosity in Non-Hydrolytic Hybrid Silicophosphate Xerogels. J. Mater. Chem. A 2015, 3 (14), 7477-7487. https://doi.org/10.1039/c4ta06823h.

(16) Machac, P.; Alauzun, J. G.; Styskalik, A.; Debecker, D. P.; Mutin, P. H.; Pinkas, J. Synthesis of High Surface Area Aluminophosphate and -Phosphonate Xerogels by NonHydrolytic Sol-Gel Reactions. Microporous Mesoporous Mater. 2021, 311. https://doi.org/10.1016/j.micromeso.2020.110682.

(17) Shylesh, S.; Samuel, P. P.; Singh, A. P. Synthesis of Hydrothermally Stable AluminiumContaining Ethane-Silica Hybrid Mesoporous Materials Using Different Aluminium Sources. Microporous Mesoporous Mater. 2007, 100 (1-3), 250-258. https://doi.org/10.1016/J.MICROMESO.2006.11.010.

(18) Styskalik, A.; Abbott, J. G.; Orick, M. C.; Debecker, D. P.; Barnes, C. E. Synthesis, Characterization and Catalytic Activity of Single Site, Lewis Acidic Aluminosilicates. Catal. Today 2018, No. November, 1-9. https://doi.org/10.1016/j.cattod.2018.11.079.

(19) Dacquin, J. P.; Cross, H. E.; Brown, D. R.; Düren, T.; Williams, J. J.; Lee, A. F.; Wilson, K. Interdependent Lateral Interactions, Hydrophobicity and Acid Strength and Their Influence on the Catalytic Activity of Nanoporous Sulfonic Acid Silicas. Green Chem. 
2010, 12 (8), 1383-1391. https://doi.org/10.1039/c0gc00045k.

(20) Wang, Y.; Alauzun, J. G.; Mutin, P. H. Water-Stable, Nonsiliceous Hybrid Materials with Tunable Porosity and Functionality: Bridged Titania-Bisphosphonates. Chem. Mater. 2020, 32 (7), 2910-2918. https://doi.org/10.1021/acs.chemmater.9b05095.

(21) Livage, J. Sol-Gel Synthesis of Heterogeneous Catalysts from Aqueous Solutions. Catal. Today 1998, 41 (1-3), 3-19. https://doi.org/10.1016/S0920-5861(98)00034-0.

(22) Debecker, D. P. Innovative Sol-Gel Routes for the Bottom-Up Preparation of Heterogeneous Catalysts. Chem. Rec. 2018, 18 (7-8), 662-675. https://doi.org/10.1002/tcr.201700068.

(23) Debecker, D. P.; Mutin, P. H. Non-Hydrolytic Sol-Gel Routes to Heterogeneous Catalysts. Chem. Soc. Rev. 2012, 41 (9), 3624-3650. https://doi.org/10.1039/C2CS15330K.

(24) Styskalik, A.; Skoda, D.; Barnes, C. E.; Pinkas, J. The Power of Non-Hydrolytic Sol-Gel Chemistry: A Review. Catalysts 2017, 7 (6), 168.

https://doi.org/10.3390/catal7060168.

(25) Skoda, D.; Styskalik, A.; Moravec, Z.; Bezdicka, P.; Babiak, M.; Klementova, M.; Barnes, C. E.; Pinkas, J. Novel Non-Hydrolytic Templated Sol-Gel Synthesis of Mesoporous Aluminosilicates and Their Use as Aminolysis Catalysts. RSC Adv. 2016, 6 (29), 2427324284. https://doi.org/10.1039/C5RA24563J.

(26) Styskalik, A.; Skoda, D.; Moravec, Z.; Barnes, C. E.; Pinkas, J. Surface Reactivity of NonHydrolytic Silicophosphate Xerogels: A Simple Method to Create Brønsted or Lewis Acid Sites on Porous Supports. New J. Chem. 2016, 40 (4), 3705-3715. 
https://doi.org/10.1039/C5NJ02928G.

(27) Styskalik, A.; Kordoghli, I.; Poleunis, C.; Delcorte, A.; Aprile, C.; Fusaro, L.; Debecker, D. P. Highly Porous Hybrid Metallosilicate Materials Prepared by Non-Hydrolytic Sol-Gel: Hydrothermal Stability and Catalytic Properties in Ethanol Dehydration. Microporous Mesoporous Mater. 2020, 297, 110028.

https://doi.org/10.1016/j.micromeso.2020.110028.

(28) Behrens, M.; Datye, A. K. Catalysis for the Conversion of Biomass and Its Derivatives; Edition open access; Ed. Open Access: Berlin, 2013.

(29) Angelici, C.; Weckhuysen, B. M.; Bruijnincx, P. C. A. Chemocatalytic Conversion of Ethanol into Butadiene and Other Bulk Chemicals. ChemSusChem 2013, 6 (9), 15951614. https://doi.org/10.1002/cssc.201300214.

(30) Sun, J.; Wang, Y. Recent Advances in Catalytic Conversion of Ethanol to Chemicals. ACS Catal. 2014, 4 (4), 1078-1090. https://doi.org/10.1021/cs4011343.

(31) Debecker, D. P.; Boissière, C.; Laurent, G.; Huet, S.; Eliaers, P.; Sanchez, C.; Backov, R. First Acidic Macro-Mesocellular Aluminosilicate Monolithic Foams "SiAI(HIPE)" and Their Catalytic Properties. Chem. Commun. 2015, 51 (74), 14018-14021. https://doi.org/10.1039/C5CC05328E.

(32) Zhang, M.; Yu, Y. Dehydration of Ethanol to Ethylene. Ind. Eng. Chem. Res. 2013, 52 (28), 9505-9514. https://doi.org/10.1021/ie401157c.

(33) Fan, D.; Dai, D. J.; Wu, H. S. Ethylene Formation by Catalytic Dehydration of Ethanol with Industrial Considerations. Materials (Basel). 2013, 6 (1), 101-115. https://doi.org/10.3390/ma6010101. 
(34) Shen, J. G. C.; Herman, R. G.; Klier, K. Sulfonic Acid-Functionalized Mesoporous Silica: Synthesis, Characterization, and Catalytic Reaction of Alcohol Coupling to Ethers. J. Phys. Chem. B 2002, 106 (39), 9975-9978. https://doi.org/10.1021/jp020131h.

(35) van Grieken, R.; Melero, J. A.; Morales, G. Etherification of Benzyl Alcohols with 1Hexanol over Organosulfonic Acid Mesostructured Materials. J. Mol. Catal. A Chem. 2006, 256 (1-2), 29-36. https://doi.org/10.1016/j.molcata.2006.04.040.

(36) Sow, B.; Hamoudi, S.; Hassan Zahedi-Niaki, M.; Kaliaguine, S. 1-Butanol Etherification Over Sulfonated Mesostructured Silica and Organo-Silica. Microporous Mesoporous Mater. 2005, 79 (1-3), 129-136. https://doi.org/10.1016/j.micromeso.2004.10.038.

(37) Liu, J.; Yang, J.; Li, C.; Yang, Q. Catalytic Applications of Sulfonic Acid Functionalized Mesoporous Organosilicas with Different Fraction of Organic Groups in the Pore Wall. J. Porous Mater. 2009, 16 (3), 273-281. https://doi.org/10.1007/s10934-008-9197-8.

(38) Styskalik, A.; Vykoukal, V.; Fusaro, L.; Aprile, C.; Debecker, D. P. Mildly Acidic Aluminosilicate Catalysts for Stable Performance in Ethanol Dehydration. Appl. Catal. B Environ. 2020, 118926. https://doi.org/10.1016/j.apcatb.2020.118926.

(39) Motevalli, M.; Ou, D. L.; Sullivan, A. C. Synthesis and Characterization of Bis(Trichlorosilylmethyl)Benzenes. J. Organomet. Chem. 1993, 445 (1-2), 35-38. https://doi.org/10.1016/0022-328X(93)80183-C.

(40) Emeis C. A. Determination of Integrated Molar Extinction Coefficients for Infrared Absorption Bands of Pyridine Adsorbed on Solid Acid Catalysts. Journal of Catalysis. 1993, pp 347-354.

(41) Rouquerol, J.; Rouquerol, F.; Sing, K. S. W. Adsorption by Powders and Porous Solids; 
Academic Press, 1998.

(42) Lowell, S. Characterization of Porous Solids and Powders: Surface Area, Pore Size and Density; Springer, 2004.

(43) Olson, D. H.; Haag, W. O.; Borghard, W. S. Use of Water as a Probe of Zeolitic Properties: Interaction of Water with HZSM-5. Microporous Mesoporous Mater. 2000 35-36, 435-446. https://doi.org/10.1016/\$1387-1811(99)00240-1.

(44) Thommes, M.; Mitchell, S.; Pérez-Ramírez, J. Surface and Pore Structure Assessment of Hierarchical MFI Zeolites by Advanced Water and Argon Sorption Studies. J. Phys. Chem. C 2012, 116 (35), 18816-18823. https://doi.org/10.1021/jp3051214.

(45) Shirley, D. A. High-Resolution X-Ray Photoemission Spectrum of the Valence Bands of Gold. Phys. Rev. B 1972, 5 (12), 4709-4714. https://doi.org/10.1103/PhysRevB.5.4709.

(46) Debecker, D. P.; Hulea, V.; Mutin, P. H. Mesoporous Mixed Oxide Catalysts via NonHydrolytic Sol-Gel: A Review. Appl. Catal. A Gen. 2013, 451, 192-206. https://doi.org/10.1016/j.apcata.2012.11.002.

(47) Crouzet, L.; Leclercq, D.; Mutin, P. H.; Vioux, A. Organic-Inorganic Materials by Nonhydrolytic Sol-Gel Processes: Organosilsesquioxane-Metal Oxide Hybrids. J. SolGel Sci. Technol. 2003, 26 (1-3), 335-338. https://doi.org/10.1023/A:1020792208751.

(48) Kriesel, J. W.; Sander, M. S.; Tilley, T. D. Block Copolymer-Assisted Synthesis of Mesoporous, Multicomponent Oxides by Nonhydrolytic, Thermolytic Decomposition of Molecular Precursors in Nonpolar Media. Chem. Mater. 2001, 13 (10), 3554-3563. https://doi.org/10.1021/cm010068t.

(49) Hirata, Y.; Sakeda, K.; Matsushita, Y.; Shimada, K.; Ishihara, Y. Characterization and 
Sintering Behavior of Alkoxide-Derived Aluminosilicate Powders. J. Am. Ceram. Soc. 1989, 72 (6), 995-1002. https://doi.org/10.1111/j.1151-2916.1989.tb06258.x.

(50) Ruiz de Sola, E.; Estevan, F.; Torres, F. J.; Alarcón, J. Effect of Thermal Treatment on the Structural Evolution of 3:2 and 2:1 Mullite Monophasic Gels. J. Non. Cryst. Solids 2005, 351 (14-15), 1202-1209. https://doi.org/10.1016/j.jnoncrysol.2005.02.017.

(51) Blackwell, C. S. Investigation of Zeolite Frameworks by Vibrational Properties. 1. The Double-Four-Ring in Group 3 Zeolites. J. Phys. Chem. 1979, 83 (25), 3251-3257. https://doi.org/10.1021/j100488a014.

(52) Handke, M.; Kowalewska, A. Siloxane and Silsesquioxane Molecules - Precursors for Silicate Materials. In Spectrochimica Acta - Part A: Molecular and Biomolecular Spectroscopy; Elsevier, 2011; Vol. 79, pp 749-757. https://doi.org/10.1016/j.saa.2010.08.049.

(53) Van Bokhoven, J. A.; Van der Eerden, A. M. J.; Koningsberger, D. C. Three-Coordinate Aluminum in Zeolites Observed with in Situ x-Ray Absorption near-Edge Spectroscopy at the Al K-Edge: Flexibility of Aluminum Coordinations in Zeolites. J. Am. Chem. Soc. 2003, 125 (24), 7435-7442. https://doi.org/10.1021/ja0292905.

(54) Wang, Z.; O’Dell, L. A.; Zeng, X.; Liu, C.; Zhao, S.; Zhang, W.; Gaborieau, M.; Jiang, Y.; Huang, J. Insight into Three-Coordinate Aluminum Species on Ethanol-to-Olefin Conversion over ZSM-5 Zeolites. Angew. Chemie Int. Ed. 2019, 58 (50), 18061-18068. https://doi.org/10.1002/anie.201910987.

(55) Hensen, E. J. M.; Poduval, D. G.; Degirmenci, V.; Ligthart, D. A. J. M.; Chen, W.; Maugé, F.; Rigutto, M. S.; Veen, J. A. R. Van. Acidity Characterization of Amorphous SilicaAlumina. J. Phys. Chem. C 2012, 116 (40), 21416-21429. 
https://doi.org/10.1021/jp309182f.

(56) Leydier, F.; Chizallet, C.; Chaumonnot, A.; Digne, M.; Soyer, E.; Quoineaud, A. A.;

Costa, D.; Raybaud, P. Brønsted Acidity of Amorphous Silica-Alumina: The Molecular Rules of Proton Transfer. J. Catal. 2011, 284 (2), 215-229.

https://doi.org/10.1016/j.jcat.2011.08.015.

(57) Chizallet, C. Towards the Atomic Scale Simulation of Intricate Acidic Aluminosilicate Catalysts. ACS Catal. 2020. https://doi.org/10.1021/acscatal.0c01136.

(58) Phung, T. K.; Busca, G. Ethanol Dehydration on Silica-Aluminas: Active Sites and Ethylene/Diethyl Ether Selectivities. Catal. Commun. 2015, 68, 110-115. https://doi.org/10.1016/J.CATCOM.2015.05.009. 